\title{
Hypercholesterolaemia - practical information for non-specialists
}

\author{
Handrean Soran ${ }^{1,2}$, Safwaan Adam ${ }^{1,2}$, Jamal B. Mohammad ${ }^{3}$, Jan H. Ho ${ }^{1,2}$, Jonathan D. Schofield ${ }^{1,2}$, \\ See Kwok ${ }^{1,2}$, Tarza Siahmansur2, Yifen Liü ${ }^{1}$, Akheel A. Syed ${ }^{1,4}$, Shaishav S. Dhage ${ }^{1,2}$, \\ Claudia Stefanutti ${ }^{5}$, Rachelle Donn ${ }^{1}$, Rayaz A. Malik ${ }^{6}$, Maciej Banach ${ }^{7}$ Paul N. Durrington ${ }^{1}$
}

\author{
${ }^{1}$ Cardiovascular Research Group, Faculty of Biology, Medicine \& Health, University \\ of Manchester, UK \\ ${ }^{2}$ Cardiovascular Trials Unit, University Department of Medicine, Manchester \\ University NHS Foundation Trust, Manchester, UK \\ ${ }^{3}$ Department of Medicine, University of Duhok, Duhok, Kurdistan region, Iraq \\ ${ }^{4}$ Department of Diabetes, Endocrinology and Obesity Medicine, Salford Royal NHS \\ Foundation Trust, Manchester, UK \\ ${ }^{5}$ Immunohematology and Transfusion Medicine, Department of Molecular Medicine, \\ University of Rome, Rome, Italy \\ ${ }^{6}$ Weill Cornell Medicine-Qatar, Doha, Qatar \\ ${ }^{7}$ Department of Hypertension, Medical University of Lodz, Poland
}

Submitted: 1 August 2017

Accepted: 3 December 2017

Arch Med Sci 2018; 14, 1: 1-21

DOI: https://doi.org/10.5114/aoms.2018.72238

Copyright (C 2017 Termedia \& Banach

\begin{abstract}
Hypercholesterolaemia is amongst the most common conditions encountered in the medical profession. It remains one of the key modifiable cardiovascular risk factors and there have been recent advances in the risk stratification methods and treatment options available. In this review, we provide a background into hypercholesterolaemia for non-specialists and consider the merits of the different risk assessment tools available. We also provide detailed considerations as to: i) when to start treatment, ii) what targets to aim for and iii) the role of low density lipoprotein cholesterol.
\end{abstract}

Key words: cardiovascualr risk, hypercholesterolaemia, lipid disorders, low density lipoprotein cholesterol, practical recommendations

\section{Introduction}

Hypercholesterolaemia is one of the major modifiable risk factors for atherosclerotic cardiovascular disease (CVD), a global health problem [1].

\section{What the non-specialist needs to know about lipids and lipoproteins}

Lipids are a heterogeneous group of naturally occurring molecules characterised by their low solubility in water and their high solubility in nonpolar (organic) solvents [2]. The major circulating lipids are cholesterol, triglycerides (triacylglycerols) and phospholipids. Because of their poor aqueous solubility, they are transported as lipoproteins, which are mixed micellar-like particles. The protein components of lipoproteins include apolipoproteins (Apos), which have structural and regulatory roles, such as modifying receptor uptake and the activity of enzymes involved in lipoprotein metabolism [2, 3]. Seventy-five percent of serum cholester-

\author{
Corresponding author: \\ Dr Handrean Soran MSc, MD, \\ FRCP \\ Consultant Physician \\ and Endocrinologist \\ Cardiovascular Trials Unit \\ The Old St \\ Mary's Hospital \\ Manchester University \\ Hospitals NHS \\ Foundation Trust \\ Manchester, M13 9WL \\ United Kingdom \\ Phone: +44 (0) 1612764443 \\ +44(0) 1612764066 \\ Fax: +44 (0) 1612763630 \\ E-mail: hsoran@aol.com; \\ Handrean.Soran@mft.nhs.uk
}


ol is produced by the liver as triglyceride rich particles in the form of very low density lipoprotein (VLDL), and after removal of the triglycerides low density lipoprotein (LDL) is formed, which circulates largely bound to apoB (Figure 1) [2-5]. LDL is cholesterol-rich, containing cholesterol derived from the liver via VLDL or by transfer from HDL in the circulation [2]. The remaining cholesterol is predominantly in VLDL and high density lipoprotein (HDL) [2]. The rate of VLDL and LDL formation is increased in obesity and with a diet high in saturated fat $[2,6]$. LDL delivers cholesterol to most tissues as it is an essential component of cell membranes and a variety of hormones e.g. oestrogen, testosterone and also vitamin D. LDL is removed from the circulation by LDL receptors (LDLR) on outer cell membranes. In adults, the liver is the major organ expressing these receptors and thus the major site of removal of LDL from the circulation. Statins, bile acid sequestrating agents and ezetimibe upregulate LDL receptors [3]. Genetic defects in LDL receptor function are the usu- al cause of familial hypercholesterolaemia (FH) [7]. HDL acquires excess cholesterol from the tissues and can return it to the liver by transfer to LDL or directly through a class of receptors distinct from the LDL receptors (Figure 1) [2, 3, 8]. This may be an atheroprotective mechanism. However, HDL also acquires cholesterol directly secreted by the liver and whether it is critically involved in reverse cholesterol transport (RCT) is currently undergoing re-evaluation. The role of HDL properties and functionality and the possible influence of this on cardiovascular disease and outcomes are also under scrutiny [9-11]. A further route for the export of hepatic cholesterol is in bile after conversion to bile salts. Cholesterol enters the intestine in bile and via the diet. Dietary triglycerides (TGs) and phospholipids are almost completely absorbed along with a smaller proportion of intestinal cholesterol. Once absorbed, cholesterol is secreted by enterocytes in triglyceride-rich chylomicrons $[2,3]$. As is the case for VLDL, their triglyceride is removed in the circulation, in this case leaving

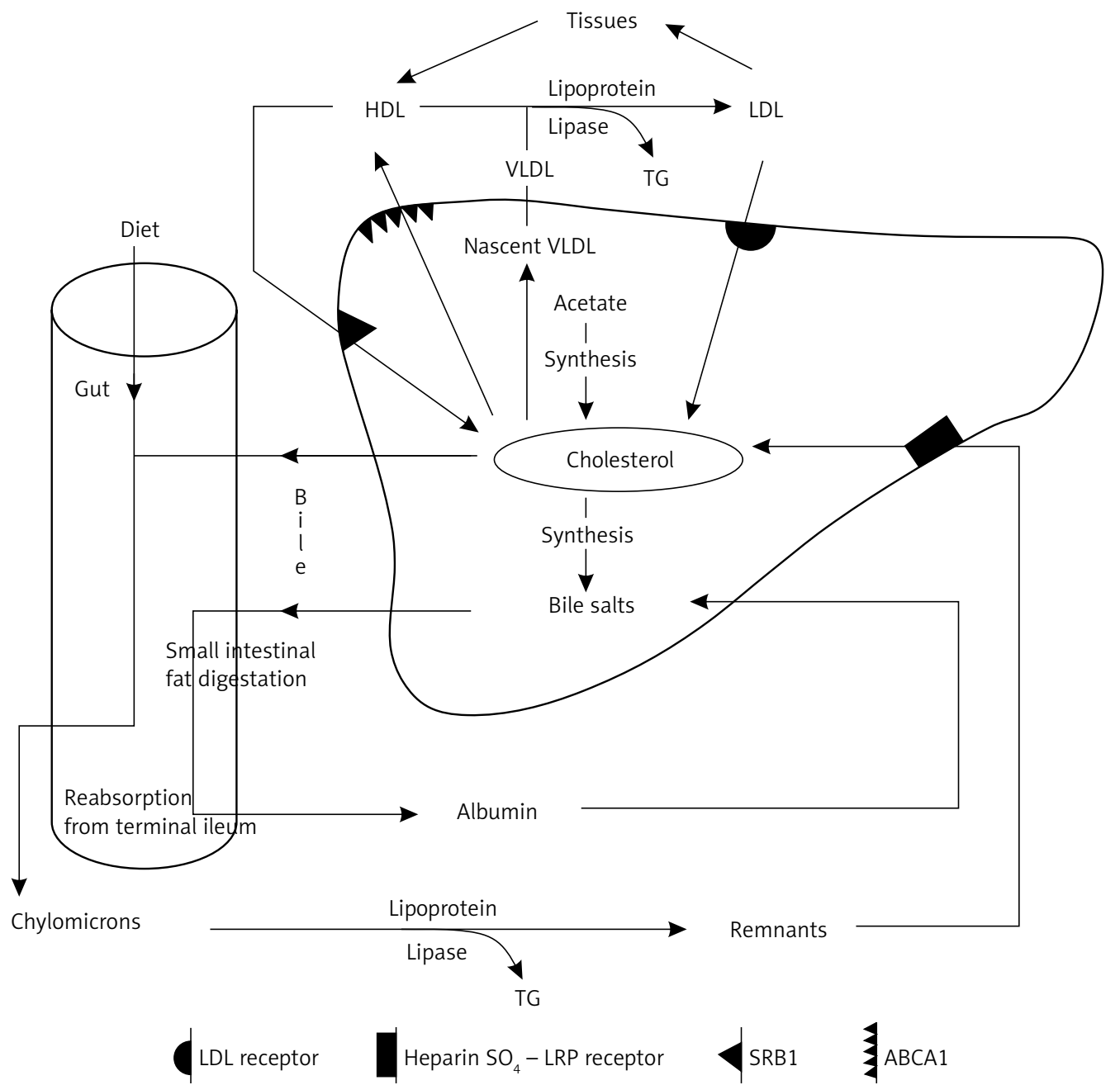

Figure 1. Lipoprotein metabolism

ABCA1 - ATP-binding cassette transporter A1, HDL - high density lipoprotein, $L D L$ - low density lipoprotein, TG - triglycerides, $S R B 1$ - scavenger receptor class $B$ type $1, V L D L$ - very low density lipoprotein. 
cholesterol-rich remnants, which are removed by the liver. In the fasting state, plasma triglycerides generally indicate the VLDL triglyceride concentration $[2,3]$.

\section{Definition of abnormal levels of cholesterol, triglycerides and HDL}

Conventionally the upper limit for laboratory reference ranges is the $95^{\text {th }}$ percentile for a healthy population. However, the incidence of clinical and clinically imminent CVD in countries such as the United Kingdom (UK) greatly exceeds $5 \%$ of the adult population [12]. Therefore, such a definition is nonsensical in the case of LDL cholesterol $(\mathrm{LDL}-\mathrm{C})$. Although there is no threshold cholesterol below which CVD risk ceases to exist, its incidence is sufficiently low in countries such as Japan and rural China, where mean adult levels of serum cholesterol are $<4 \mathrm{mmol} / \mathrm{l}(155 \mathrm{mg} / \mathrm{dl})$ and of LDL-C < $2 \mathrm{mmol} / \mathrm{l}(77 \mathrm{mg} / \mathrm{dl})$ to regard them as healthy in this respect [13-15]. The mean serum cholesterol and LDL cholesterol in the UK are $5.9 \mathrm{mmol} / \mathrm{l}(228$ $\mathrm{mg} / \mathrm{dl})$ and $3.7 \mathrm{mmol} / \mathrm{l}(143 \mathrm{mg} / \mathrm{dl})$ respectively in middle-age [16]. Thus in $80 \%$ of adult population, serum cholesterol exceeds $4 \mathrm{mmol} / \mathrm{l}(155 \mathrm{mg} / \mathrm{dl})$ and the LDL cholesterol $2 \mathrm{mmol} / \mathrm{l}(77 \mathrm{mg} / \mathrm{dl})$, which are increasingly accepted as the upper limits for healthy levels of serum and LDL cholesterol [16]. In comparison, recent data from the LIPIDOGRAM 2015 cohort study in Poland reported mean cholesterol and LDL-C levels of $5.2 \mathrm{mmol} / \mathrm{l}(202 \mathrm{mg} / \mathrm{dl})$ and $3.31 \mathrm{mmol} / /(128 \mathrm{mg} / \mathrm{dl})$, respectively in consecutive adult patients from primary care [17]. In city dwellers in China, obesity and increasing saturated fat consumption are causing rapid increases in LDL-C and accelerated rates of atherosclerotic CVD (ASCVD) [15]. A similar phenomenon occurs when Japanese migrate to the United States, or Indians to the UK $[18,19]$. The evidence from randomised controlled trials (RCT's) of statins unequivocally demonstrates benefit for lowering LDL cholesterol levels to less than $1.8 \mathrm{mmol} / \mathrm{l}(70 \mathrm{mg} /$ $\mathrm{dl})$, when absolute CVD risk is high [20, 21].

The upper limit of normal for triglycerides is generally considered to be $1.7 \mathrm{mmol} / \mathrm{l}(151 \mathrm{mg} /$ $\mathrm{dl}$ ), a level beyond which at which they begin to be associated with a smaller, more atherogenic LDL (small dense LDL - sdLDL) [22]. Much higher levels, generally > $10 \mathrm{mmol} / \mathrm{l}(886 \mathrm{mg} / \mathrm{dl})$, are associated with acute pancreatitis [2]. The lower limit of normal for $\mathrm{HDL}-\mathrm{C}$ is $1.0 \mathrm{mmol} / \mathrm{l}(39 \mathrm{mg} / \mathrm{dl})$ in men and $1.3 \mathrm{mmol} / \mathrm{l}(50 \mathrm{mg} / \mathrm{dl})$ in women [23]. HDL is decreased and serum TGs are increased in several hyperlipidaemias associated with increased CVD risk, but evidence that drugs which raise HDL or lower triglycerides diminish this risk is unclear $[22,24]$. LDL cholesterol lowering with statins is just as effective in decreasing relative CVD risk as in patients without raised triglycerides or low HDL. Therefore, they prevent even more events because of the higher absolute CVD risk when hypertriglyceridaemia and/or low HDL are present [20-24]. Non-HDL cholesterol includes all known atherogenic lipoproteins. Non-HDL cholesterol has been emphasised as an important therapeutic target by some treatment guidelines [25-27]. It can accurately be derived from a non-fasting specimen and therefore does not require any special preparation by the patient.

\section{Nutritional and genetic contribution to hyperlipidaemia}

The most likely explanation for the variation in serum cholesterol in different populations is due to nutrition and diminished energy expenditure [2]. The consumption of fat, particularly saturated fat, increased dramatically in the West from the end of the $19^{\text {th }}$ century before which coronary heart disease (CHD) death was still uncommon [2, 28].

At birth LDL-C levels are similar throughout the world at around $1 \mathrm{mmol} / \mathrm{l}(39 \mathrm{mg} / \mathrm{dl})$ [29]. During childhood, however, there is a greater rise in LDL-C in countries such as the United Kingdom and United States, and autopsies reveal widespread atheroma even in children in these countries [30]. Genes also play a part, but major monogenic disorders of cholesterol metabolism, such as FH, although important clinically, do not account for the majority of hyperlipidaemia and CVD [31]. In the population as a whole, it has been estimated from twin and other genetic studies that the hereditability of LDL-C is around $40 \%$ [32], suggesting that this is the proportion of person-to-person variability explained by inheritance alone with non-inherited factors (e.g. lifestyle) contributing considerably. Nutrition and different patterns of energy expenditure rather than genes are generally considered sufficient to explain the substantial differences in LDL between different populations, but one exception to this is the increased prevalence of proprotein convertase subtilisin/kexin type 9 (PCSK9) loss of function gene variants associated with lower LDL-C in Americans of African descent [33].

\section{Screening for hyperlipidaemia}

It is generally considered advisable for the whole population to be screened for dyslipidaemia as part of CVD risk assessment from the age of 40 years $[26,34,35]$. Those whose risk is borderline for treatment should be followed up more closely according to individual circumstances. Otherwise they should be reassessed every 5 years. Some hyperlipidaemias, such as $\mathrm{FH}$, should be detected earlier, ideally in childhood [7]. Cascade family screening from known probands with $\mathrm{FH}$ should 
be undertaken through Lipid Clinics (or ambulatory Lipid or Metabolic Disorders Clinics) with the cooperation of family doctors [7]. Patients suspected of having $\mathrm{FH}$ (Box 2) or any other severe dyslipidaemia should be referred for specialist assessment [7, 36].

\section{Primary dyslipidaemias}

Table I provides a clinically relevant classification of primary dyslipidaemias [2, 36-39].

\section{Common (polygenic) hypercholesterolaemia}

The commonest cause of hypercholesterolaemia is overproduction of VLDL leading to increased LDL [2]. Polymorphic variants within certain genes may influence lipoprotein production or clearance in the presence of nutritional excess relative to energy expenditure $[40,41]$. If the mechanism for conversion of VLDL to $L D L$ is uncompromised, LDL-C alone will be raised, particularly so with gene variants associated with diminished LDL catabolism. VLDL (triglycerides) will also be increased if gene variants impede the conversion of VLDL to LDL [2]. The CVD risk associated with LDL-C is increased when TGs are also raised. If relatives of a patient with a combined increase in LDL cholesterol and triglycerides are screened, some will have principally hypertriglyceridae- mia, some raised LDL alone, others a combined increase whilst some will have relatively normal lipids, depending on the particular combination of polygenic characteristics each has inherited. This is termed familial combined hyperlipidaemia (FCH) [2, 34]. Often hypertriglyceridaemia is associated with central obesity, which, by causing insulin-resistance, is responsible for its clustering with other risk factors such as low levels of HDL, raised blood pressure (BP) and dysglycaemia manifest by either overt type 2 diabetes (T2DM) or prediabetes [23]. CVD risk is increased in this prodromal period, often years before diabetes develops [42]. Metabolic syndrome (MetS) is often defined as the coexistence of three or more of the following: waist circumference $>102 \mathrm{~cm}$ in men or $>88 \mathrm{~cm}$ in women, fasting triglycerides $\geq 1.7 \mathrm{mmol} / \mathrm{l}$ (150 mg/dl), HDL cholesterol < $1.0 \mathrm{mmol} / \mathrm{l}(39 \mathrm{mg} / \mathrm{dl})$ in men and $1.3 \mathrm{mmol} / \mathrm{l}(50 \mathrm{mg} / \mathrm{dl})$ in women, $\mathrm{BP} \geq 130 / 85 \mathrm{~mm} \mathrm{Hg}$ and/or fasting glucose $\geq 5.6 \mathrm{mmol} / \mathrm{l}(101 \mathrm{mg} / \mathrm{dl})$ or use of medication for hyperglycaemia [43]. The concept of metabolic syndrome recognises the clustering of CVD risk factors [43]. The hyperlipidaemia associated with T2DM was formerly described as secondary, but it is now obvious that type 2 diabetes should be viewed as part of a dyslipidaemic syndrome. There is clearly overlap between $\mathrm{FCH}$, metabolic syndrome and T2DM [44-46].

Table I. More commonly encountered causes of primary hypercholesterolaemia. Prevalence approximate and refers to adult population

\begin{tabular}{|c|c|c|c|c|}
\hline Diagnosis & Prevalence & Inheritance & Clinical features & Biochemistry \\
\hline $\begin{array}{l}\text { Common } \\
\text { hypercholesterolaemia }\end{array}$ & $70 \%$ & Polygenic & $\begin{array}{l}\text { Usually none (sometimes } \\
\text { corneal arcus, } \\
\text { xanthelasmata) }\end{array}$ & $\begin{array}{l}\text { Raised cholesterol } \\
\text { due to LDL }\end{array}$ \\
\hline $\begin{array}{l}\text { Familial } \\
\text { hypercholesterolaemia } \\
\text { (also called } \\
\text { autosomal dominant } \\
\text { hypercholesterolaemia) }\end{array}$ & $0.2 \%$ & Monogenic & Tendon xanthomata & $\begin{array}{l}\text { Raised cholesterol } \\
\text { due to LDL }\end{array}$ \\
\hline $\begin{array}{l}\text { Familial defective } \\
\text { apolipoprotein B }\end{array}$ & $0.2 \%$ & Monogenic & $\begin{array}{l}\text { Usually none (occasionally } \\
\qquad \text { FH phenotype) }\end{array}$ & $\begin{array}{l}\text { Raised cholesterol } \\
\text { due to LDL }\end{array}$ \\
\hline $\begin{array}{l}\text { Combined } \\
\text { hyperlipidaemia }\end{array}$ & $10 \%$ & Polygenic & $\begin{array}{c}\text { Usually none } \\
\text { (sometimes corneal arcus, } \\
\text { xanthelasmata) } \\
\text { Overlap with dyslipidaemia } \\
\text { of type } 2 \text { diabetes and } \\
\text { metabolic syndrome }\end{array}$ & $\begin{array}{c}\text { Raised triglycerides } \\
\text { and cholesterol } \\
\text { due to increased VLDL }\end{array}$ \\
\hline $\begin{array}{l}\text { Type III } \\
\text { hyperlipoproteinaemia } \\
\text { (dysbetalipoproteinaemia; } \\
\text { remnant particle disease) }\end{array}$ & $0.02 \%$ & Monogenic & $\begin{array}{l}\text { Striate palmar xanthomata. } \\
\text { Tuberoeruptive xanthomata }\end{array}$ & $\begin{array}{l}\text { Raised triglycerides and } \\
\text { cholesterol due to IDL and } \\
\text { chylomicron remnants }\end{array}$ \\
\hline $\begin{array}{l}\text { Severe } \\
\text { hypertriglyceridaemia } \\
\text { (>10 } \mathrm{mmol} / \mathrm{l})\end{array}$ & $0.1 \%$ & $\begin{array}{l}\text { Polygenic/ } \\
\text { monogenic* }\end{array}$ & $\begin{array}{l}\text { Eruptive xanthomata, acute } \\
\text { pancreatitis }\end{array}$ & $\begin{array}{l}\text { Raised triglycerides due to } \\
\text { fasting chylomicronaemia } \\
\text { and increased VLDL }\end{array}$ \\
\hline
\end{tabular}




\section{Monogenic disorders causing raised cholesterol}

For famililal hypercholesterolaemia see Boxes 1-3, familial dysbetalipoproteinaemia - Box 4, and for severe hypertriglicerydaemia - Box 5.

Box 1. Familial hypercholesterolaemia (also called autosomal dominant hypercholesterolaemia) $[2,4,26,37,41,54]$

\section{Heterozygous familial hypercholesterolaemia $(\mathrm{HeFH})$ :}

- HeFH is the most common monogenic cause of raised serum cholesterol, affecting about 1 in 250 to 1 in 500 people. It is dominantly inherited.

- Affected family members have LDL cholesterol levels typically double those of unaffected first degree relatives. Serum cholesterol is thus commonly $9-12 \mathrm{mmol} / \mathrm{l}(348-464 \mathrm{mg} / \mathrm{dl})$ in affected adults. It is higher from birth and $\mathrm{HeFH}$ can be diagnosed in childhood.

- Untreated it results in tendon xanthomata typically in the Achilles tendons (Achilles tendon pain may be first manifestation) [19] and extensor tendons on the dorsum of the hands. Subperiosteal xanthoma are also sometimes present on the tibial tuberosities.

- CVD occurs with increasing frequency from the third decade so that without medical intervention over half of affected men and $15 \%$ of affected women die before the age of 60 years.

- The clinical syndrome of HeFH results from defective LDL catabolism. Most cases are due to mutation of the LDL receptor.

- A smaller proportion are due to mutations of the apoB100 gene (familial defective apolipoprotein B), which interferes with its binding to the LDL receptor. The most common of these is apoB3500, but it is only a minority of heterozygotes with this who express hypercholesterolemia of such severity as to cause HeFH. On the other hand, gain-of-function mutations of proprotein convertase subtilisin kexin 9 (PCSK9), an uncommon cause of HeFH, often cause an unusually severe phenotype. PCSK9 is involved in the degradation of hepatic LDL receptors.

- HeFH does not require obesity for its expression and affected individuals often do not conform to the typical CVD-prone clinical phenotype, appearing deceptively lean and physically fit.

- There has been a dramatic reduction in premature mortality coincident with the introduction of statin therapy.

- Cascade family screening is indicated.

Homozygous Familial Hypercholesterolemia (HoFH):

- HoFH is rare; 1 in 500000 to 1 in 300000 (unless there is consanguinity).

- Both LDL receptor genes are mutated. LDL cholesterol is greatly increased.

- Tendon and planar xanthomata develop in young children and CVD may occur even before adolescence.

- Survival into adulthood is generally only possible if treatment with extracorporeal removal of LDL is available. Autosomal recessive hypercholesterolemia (ARH):

- Rare, generally occurs only in people of Sardinian descent.

- Due to dysfunction of an adaptor protein (ARH protein) required for receptor-mediated hepatic uptake of LDL.

- Finds little expression in heterozygotes, but in homozygotes is almost as severe as HoFH.

Box 2. Simon Broome Familial Hypercholesterolemia Register diagnostic criteria for heterozygous familial hypercholesterolaemia $(\mathrm{HeFH})$

\begin{tabular}{|ll|}
\hline Criteria & \multicolumn{1}{c|}{ Description } \\
\hline A & Total cholesterol concentration $>7.5 \mathrm{mmol} / \mathrm{l}$ in adults or $>6.7 \mathrm{mmol} / \mathrm{l}$ in children aged $<16$ years, or \\
\cline { 2 - 3 } & Low density lipoprotein cholesterol concentration $>4.9 \mathrm{mmol} / /$ in adults or $>4.0 \mathrm{mmol} / \mathrm{l}$ in children \\
\hline B & Tendinous xanthomata in patient or first-degree relative \\
\hline C & DNA-based evidence of mutation in $L D L R$ \\
\hline D & $\begin{array}{l}\text { Family history of myocardial infarction }<50 \text { years in second-degree relative or }<60 \text { years in first- } \\
\text { degree relative }\end{array}$ \\
\hline E & Family history of raised total cholesterol concentration $\geq 7.5 \mathrm{mmol} / /$ in first- or second-degree relative \\
\hline Diagnosis & \\
\hline A + B or C constitutes a definite diagnosis of HeFH \\
\hline A + D or A + E constitute probable HeFH \\
\hline
\end{tabular}


H. Soran, S. Adam, J.B. Mohammad, J.H. Ho, J.D. Schofield, S. Kwok, T. Siahmansur, Y. Liu, A.A. Syed, S.S. Dhage, C. Stefanutti, R. Donn, R.A. Malik, M. Banach, P.N. Durrington

Box 3. Criteria for the diagnosis of HeFH according to Dutch Lipid Clinic Network (adapted from 2016 ESC/EAS guidelines for the management of dyslipidaemias) [54]

\begin{tabular}{|c|c|c|}
\hline Variable & Criteria & Score \\
\hline \multirow[t]{2}{*}{ Family history } & $\begin{array}{l}\text { First-degree relative with premature } C A D^{*} \text {, } \\
\text { or first degree relative with } L D L-C>95^{\text {th }} \text { centile }\end{array}$ & 1 \\
\hline & $\begin{array}{l}\text { First-degree relative with tendon xanthomata and/or corneal arcus, } \\
\text { or children }<18 \text { years with } L D L-C>95^{\text {th }} \text { centile }\end{array}$ & 2 \\
\hline \multirow[t]{2}{*}{ Clinical history } & Premature $C A D^{*}$ & 2 \\
\hline & Premature cerebral or peripheral vascular disease* & 1 \\
\hline \multirow[t]{2}{*}{ Physical examination } & Tendon xanthomata & 6 \\
\hline & Corneal arcus $<45$ years & 4 \\
\hline \multirow[t]{4}{*}{ LDL-C } & $>8.5 \mathrm{mmol} / \mathrm{l}(>325 \mathrm{mg} / \mathrm{dl})$ & 8 \\
\hline & $6.5-8.4 \mathrm{mmol} / \mathrm{l}(251-325 \mathrm{mg} / \mathrm{dl})$ & 5 \\
\hline & $5.0-6.4 \mathrm{mmol} / \mathrm{l}(191-250 \mathrm{mg} / \mathrm{dl})$ & 3 \\
\hline & $4.0-4.9 \mathrm{mmol} / \mathrm{l}(155-190 \mathrm{mg} / \mathrm{dl})$ & 1 \\
\hline DNA analysis & Functional mutation in LDLR, apoB or PCSK9 gene & 8 \\
\hline Definite FH & Score $>8$ & \\
\hline Probable FH & Score 6-8 & \\
\hline Possible FH & Score 3-5 & \\
\hline No diagnosis & Score $<3$ & \\
\hline
\end{tabular}

${ }^{*}$ Male $<55$ years, female < 60 years. CAD - coronary artery disease, LDL-C - low density lipoprotein cholesterol.

Box 4. Familial dysbetalipoproteinaemia (syn. remnant removal disease; type III hyperlipoproteinaemia)

- Severe hypercholesterolaemia associated with marked hypertriglyceridaemia, unmatched by increases in apoB100.

- Chylomicron remnants accumulate in the circulation.

- Tuberoeruptive xanthomata typically on the knees and elbows, but occasionally more widely distributed, and deposits of cholesterol in the palmar skin creases (striate palmar xanthomata).

- The risk of early onset CVD and peripheral arterial disease are greatly increased.

- Affected patients have genetic variants of apoE with diminished receptor binding, the most common of which is $A P O E 2$.

- Other factors predisposing to hyperlipidaemia, such as obesity, are often also present and the condition is exceptionally rare in women before the menopause.

Box 5. Severe hypertriglyceridaemia $[2,22,38]$

- Severe hypertriglyceridaemia (serum triglyceride $\geq 10 \mathrm{mmol} / \mathrm{l}$ ).

- The capacity of lipoprotein lipase to clear triglyceride from the circulation is exceeded.

- Both chylomicrons and VLDL are dependent on lipoprotein lipase for removal of their triglycerides. Thus both contribute to the hypertriglyceridaemia even in the fasting state.

- Associated with acute pancreatitis, hepatosplenomegaly, lipaemia retinalis, eruptive xanthomata and a milky appearance to serum and plasma.

- It can be monogenic or polygenic.

- Rarely it is due to Familial Lipoprotein Lipase Deficiency (FLLD) (also known as familial chylomicronemia syndrome - FCS) in which mutations of both lipoprotein lipase genes severely impair triglyceride clearance. It may present in childhood.

- More commonly it occurs in adults who have genetic variants diminishing lipoprotein lipase activity less severely than in FLLD, but in combination with factors which increase triglyceride entry into the circulation (high fat diet, obesity, type 2 diabetes, high alcohol consumption) or compromise lipoprotein lipase function (insulin deficiency or resistance, hypothyroidism, $\beta$-adrenoceptor blockade).

- Lipodystrophy syndromes (acquired, familial, partial and general) are associated with severe insulin resistance and hypertriglyceridaemia. 


\section{Treatment strategies}

\section{Dietary treatment}

All obese hyperlipidaemic patients benefit from weight loss, which must involve restriction of excess energy intake [47, 48]. Generally fat contributes most to calorific excess, but food and drink rich in carbohydrate, especially refined carbohydrate, can be a major source of excess energy intake in overweight children who undertake very limited physical activity [49]. In lean patients with hyperlipidaemia, dietary saturated fat and cholesterol should particularly be avoided, because they tend to raise LDL-C. However, a meta-analysis revealed that even under metabolic ward conditions the reduction in LDL that can be expected from an isocaloric decrease in dietary saturated fat and cholesterol is small [50]. Whilst this consideration has prompted some to denigrate the value of diet [51], a number of dietary trials, particularly when monounsaturates are substituted, have shown substantially decreased CVD incidence [52]. In patients with severe hypertriglyceridaemia, all fat should be restricted to limit chylomicron formation, which contributes substantially to the hyperlipidaemia $[2,38]$. Advice to curb excessive alcohol intake should also be given $[2,22,38]$. Long chain omega-3 fatty acids have no effect on LDL-C levels, but in pharmacological doses purified preparations lower triglycerides even in patients receiving statins [53].

\section{Drug treatment}

The decision to go beyond dietary advice and introduce lipid-lowering medication is based on an assessment of risk so that treatment is deployed in those who will benefit the most [26, 54]. Because the evidence from RCT's of the benefit of statins $[20,21,55,56]$ is indisputable, one may think that the indications for statins should be relatively simple to execute. Deficiencies, however, persist in our knowledge of how to achieve the greatest population impact with statins, mostly around how to estimate CVD risk, issues of cost-effectiveness and misinterpretation of the clinical trial evidence. Resort is often made by the composers of guidelines to the use of 'clinical judgement'. But how is the clinician to employ such judgement without an accurate knowledge of the relevant areas of agreement and controversy? Numerous national and international guidelines for the management of dyslipidaemia are listed on the International Atherosclerosis Society Website [www.athero. org/guidel2.asp]. We shall focus on those from the USA [25, 57], Europe [54] and Britain [7, 26, $35,58]$, because most of other guidelines are derived from these.
People whose clinical diagnosis provides an indication for lipid-lowering medication

There is general agreement in national and international recommendations that people are at high enough CVD risk for statin treatment if they have:

(i) Known atherosclerotic CVD (CHD, stroke, TIA and peripheral arterial disease) $[25,26,34$, 57, 58].

(ii) Type 1 diabetes for longer than 10 years, age $\geq 40$ years, presence of microalbuminuria, or established nephropathy or other major cardiovascular risk factors [26, 35, 57, 58].

(iii) Monogenic hyperlipidaemias (which include familial hypercholesterolaemia) and very high cholesterol (defined by NICE [26] and the European recommendations [54] as $\geq 8 \mathrm{mmol} / \mathrm{l}$ (309 mg/dl). Although this is unsatisfactory because many women have a high total cholesterol because of high HDL [59]. It is better to define this indication in terms of LDL cholesterol or the total serum cholesterol: HDL ratio. In the USA, an LDL cholesterol $>4.9 \mathrm{mmol} / \mathrm{l}$ (> $190 \mathrm{mg} / \mathrm{dl}$ ) is regarded as a statin indication with an option to treat at $>4.1 \mathrm{mmol} / \mathrm{l}$ (>160 mg/dl) [57]. These values would be too low to adopt in the UK, where the average LDL cholesterol in middle-aged men and women is around $3.7 \mathrm{mmol} / \mathrm{l}$ [16].

(iv) The European recommendations indicate that patients with chronic kidney disease should receive statin therapy [54] (see secondary hyperlipidaemia).

People in whom CVD risk assessment using lipids and other risk factors should be undertaken

There is general agreement that in people without established CVD (in the UK these include type 2 diabetes) an assessment of CVD risk should be made using a multivariate mathematical model, which incorporates other risk factors. There are several such models, which differ according to the risk factors they incorporate and they have been variously translated to facilitate their use in clinical practice. In the USA a points system based on the Framingham Heart Study (FHS) is employed to give the 10-year likelihood of CHD (fatal and non-fatal myocardial infarction) as rate per 100 (\%) over 10 years [57]. The USA guidance relies less on risk estimation and more on the LDL cholesterol level than do British and European recommendations. In the UK, NICE [26] has left practitioners to choose from:

- Joint British Societies' consensus recommendations (JBS3 [http://www.jbs3risk.com]) which offers a Framingham-based method of risk assessment. 
- A calculated lifetime risk based on QRISK Lifetime (http://www.qrisk.org/lifetime/), (QRISK2 (an algorithm based on an amalgamated UK general practice database) [http://www.qrisk. org/]) [60].

- ASSIGN (an algorithm based on an amalgam of Scottish epidemiological studies, the Scottish Heart Extended Cohort) [http://assign-score. com/].

All three give CVD risk (fatal and non-fatal CHD, stroke and TIA) as a rate per 100 (\%) over 10 years. NICE recommends CVD risk evaluation up until the age of 74 years [26]. QRISK2 has now been updated to QRISK3, which in addition to the original risk factors, incorporates additional conditions including erectile dysfunction, severe mental illness, use of atypical antipsychotics, use of corticosteroids, systemic lupus erythematosus, migraine, chronic kidney disease (starting at stage 3) and blood pressure variability (https://www.qrisk. org/three). Despite QRISK3 having been recently validated [61], the latest NICE guidance still advocates for the use of QRISK2 hence this will be the version assessed in this review. In Europe, the Systematic Coronary Risk Estimation (SCORE) [54] charts are recommended. Despite their name, these estimate the 10-year risk of fatal CVD (CHD, stroke or other occlusive arterial disease) as rate per 100 (\%) over 10 years. The 2013 American College of Cardiology/American Heart Association (ACC/AHA) Task Force developed risk equations for non-Hispanic African-American and White men and women aged 40 to 79 . The 10-year risk estimation was based on non-fatal myocardial infarction, CHD death, fatal and non-fatal stroke [62]. It should be noted that different outcomes for risk calculation are in use in the USA, UK and Europe, which means that the risk calculation methods can only be used with the guideline for which they were designed [63]. Even then the population impact of statins will vary according to which guidelines are adopted [64].

\section{LDL cholesterol threshold for initiation of lipid-lowering medication when CVD risk is high}

There is general agreement in Europe and the USA that the threshold for initiating statin treatment (for very high risk patients) should be LDL-C of $>1.8 \mathrm{mmol} / \mathrm{l}(>70 \mathrm{mg} / \mathrm{dl})$ and the target of treatment should be LDL cholesterol $<1.8 \mathrm{mmol} / \mathrm{l}$ $(<70 \mathrm{mg} / \mathrm{dl})[54,57]$. However, recently, based on the data from the FOURIER (Further Cardiovascular Outcomes Research with PCSK9 Inhibition in Subjects with Elevated Risk) trial there has been a suggestion to lower this target to less than $1.3 \mathrm{mmol} / \mathrm{l}(50 \mathrm{mg} / \mathrm{dl})$ or even lower [65-67]. In the UK, JBS3 [35] recommended a target of non-
$\mathrm{HDL}$ cholesterol level of $<2.5 \mathrm{mmol} / \mathrm{l}(97 \mathrm{mg} / \mathrm{dl})$ (broadly equivalent to LDL-C of $<1.8 \mathrm{mmol} / \mathrm{l}$ (70 $\mathrm{mg} / \mathrm{dl})$ ) while NICE advocates a $40 \%$ reduction in non-HDL cholesterol [26]. LDL-C is measured directly in some laboratories, but more often is calculated using the Friedewald formula (Box 6). This formula, which requires fasting triglycerides to be measured, cannot be used when fasting triglycerides exceed $4.5 \mathrm{mmol} / \mathrm{l}$. There have been attempts to improve LDL-C estimation without the limitations associated with the Friedewald formula [68]. Apolipoprotein $B(a p o B)$, the major protein component of VLDL and LDL and the ligand which allows arterial wall macrophage uptake of $L D L$, is unaffected by fasting or hypertriglyceridaemia. Furthermore, there is evidence that statin trial outcomes are more closely related to apoB rather than to LDL-C [69]. In North America [70, 71] an apoB target of 80 $\mathrm{mg} / \mathrm{dl}$ has been proposed to replace LDL cholesterol, however the costs of this measurements remain an issue in comparison to LDL-C evaluation. An alternative is to use non-HDL cholesterol as a target. This performs almost as well as apoB, is also unaffected by fasting or hypertriglyceridaemia and does not require any additional laboratory methodology, since it is calculated simply by subtracting HDL-C from non-fasting or fasting serum total cholesterol and indeed non-HDL cholesterol is currently the therapeutic target for both JBS3 and NICE (Box 6). Non-HDL cholesterol thresholds are set $0.8 \mathrm{mmol} / \mathrm{l}$ (30 $\mathrm{mg} / \mathrm{dl}$ ) higher than those of LDL cholesterol. Thus, an LDL cholesterol of $1.8 \mathrm{mmol} / \mathrm{l}(70 \mathrm{mg} / \mathrm{dl})$ is equivalent to a non-HDL cholesterol of $2.6 \mathrm{mmol} / \mathrm{l}$ $(100 \mathrm{mg} / \mathrm{dl})[34,72]$.

Box 6. Useful formulae

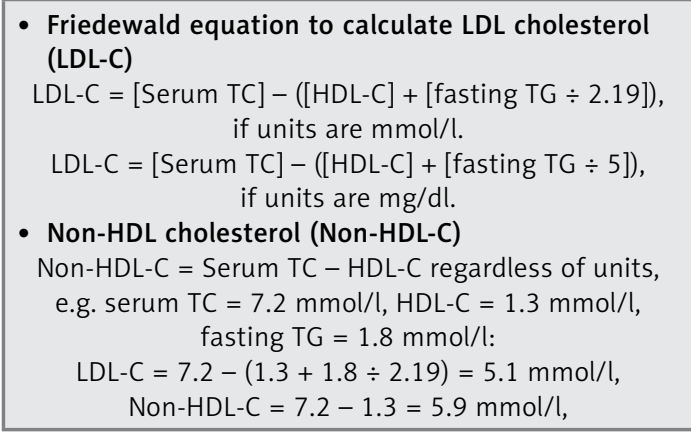

\section{LDL-C targets: how low should we go?}

\section{Is there an LDL-C level beyond which CVD risk reduction ceases?}

The European Society of Cardiology (ESC) and United States National Lipid Association guidelines propose aiming for an LDL-C of $1.8 \mathrm{mmol} / \mathrm{l}$ $(70 \mathrm{mg} / \mathrm{dl})[25,73]$. Findings from meta-analyses suggest that the relationship between LDL-C and CVD is likely to be curvilinear leading to the as- 
sumption that with lower LDL-C levels there should be a further reduction in CVD events [21, 74-76].

Interestingly, a meta-analysis of 8 randomised statin trials by Boekholdt et al. demonstrated that when 3 groups were considered according to LDL-C levels, the adjusted hazard ratios were 0.56 (LDL-C achieved 1.9 to $<2.6 \mathrm{mmol} / \mathrm{l}$ (73 to $<101$ $\mathrm{mg} / \mathrm{dl})$ ), 0.51 (LDL-C achieved 1.3 to $<1.9 \mathrm{mmol} / \mathrm{l}$ (50 to $<73 \mathrm{mg} / \mathrm{dl})$ ) and 0.44 (LDL-C achieved $<1.3 \mathrm{mmol} / \mathrm{l}(<50 \mathrm{mg} / \mathrm{dl}))$ when compared to those individuals who had LDL-C levels $>4.5 \mathrm{mmol} / \mathrm{l}$ $(174 \mathrm{mg} / \mathrm{dl})$ [77]. Furthermore, findings from randomised statin trials also show that CVD incidence was reduced in those with the lowest LDL-C [78-80]. This finding is corroborated in non-statin trials with ezetimibe in the IMPROVE-IT (The Improved Reduction of Outcomes: Vytorin Efficacy International Trial) trial when additional LDL-C lowering resulted in a statistically significant reduction in CVD events [81]. Of note, pooled data from 10 trials of the proprotein convertase subtilisin/kexin type 9 (PCSK9) inhibitor alirocumab support the notion that the relation between $L D L-C$ reduction and CVD risk decline is a continuum even when LDL-C levels below $1.3 \mathrm{mmol} / \mathrm{l}(50 \mathrm{mg} / \mathrm{dl})$ are achieved $(33 \%$ of participants) [82]. The risk reduction for every $1 \mathrm{mmol} / \mathrm{l}$ absolute reduction in LDL-C was $24 \%$ which is consistent with previous meta-analyses $[21,74,82,83]$. Similarly, with the other available PCSK9 inhibitor, evolocumab, both the FOURIER and GLAGOV (Global Assessment of Plaque Regression with a PCSK9 Antibody as Measured by Intravascular Ultrasound) trials showed that there was no attenuation of CVD benefit with intense LDL-C lowering even as low as $0.52 \mathrm{mmol} / \mathrm{l}(20 \mathrm{mg} / \mathrm{dl})$ $[67,84]$. Furthermore, the recently reported REVEAL (Randomized Evaluation of the Effects of Anacetrapib through Lipid Modification) trial using Anacetrapib (a Cholesterol Ester Transfer Protein (CETP) inhibitor) adds further evidence to the concept that aiming to achieve greater reductions in LDL-C $(1.8 \mathrm{mmol} / \mathrm{l}$ or $70 \mathrm{mg} / \mathrm{dl})$ may confer even greater CVD protection [85]. Higher risk patients benefit more from intensive $L D L-C$ reduction to very low levels [86]. Figure 2 shows that the consistency of the previously established evidence (from meta-analyses) of a CV risk reduction of about one-fifth for every $1 \mathrm{mmol} / \mathrm{l}(38 \mathrm{mg} / \mathrm{dl})$ reduction in LDL-C remains even when baseline LDL-C levels are low $[21,74]$.

\section{Safety of low LDL-C levels}

The apprehension with aiming for such low LDL-C levels is the potential for adverse effects to occur. Patients with familial hypobetalipoproteinaemia (who have genetically determined very low LDL-C since birth) levels have been shown to have a tendency towards hepatic steatosis whilst those with abetalipoproteinaemia (another ge- netic condition manifest by very low $L D L-C$ ) have difficulty in transporting vitamins $A$ and $E[76$, 87]. In contrast, patients with a rare loss-of- function PCSK9 mutation and very low LDL-C display no ill-effects and indeed have relative protection against CVD [76, 87].

Specific concerns about the safety of intensive $L D L-C$ reduction arose from a post-hoc analysis of the JUPITER (Justification for the Use of Statins in Primary Prevention: An Intervention Trial Evaluating Rosuvastatin) trial in which subjects whose LDL-C was below $0.78 \mathrm{mmol} / \mathrm{l}(30 \mathrm{mg} / \mathrm{dl})$ with Rosuvastatin therapy were more commonly found to have type 2 diabetes $(H R=1.56$; $p=0.01)$ and haematuria $(H R=2.10 ; p<0.001)$ as well as insomnia, hepatobiliary and psychiatric disorders [88]. Additionally, concern was raised about the possibility of neurocognitive deficit from the OSLER (Open-Label Study of Long-Term Evaluation against LDL Cholesterol) trials of evolocumab albeit apparently independent of LDL-C.

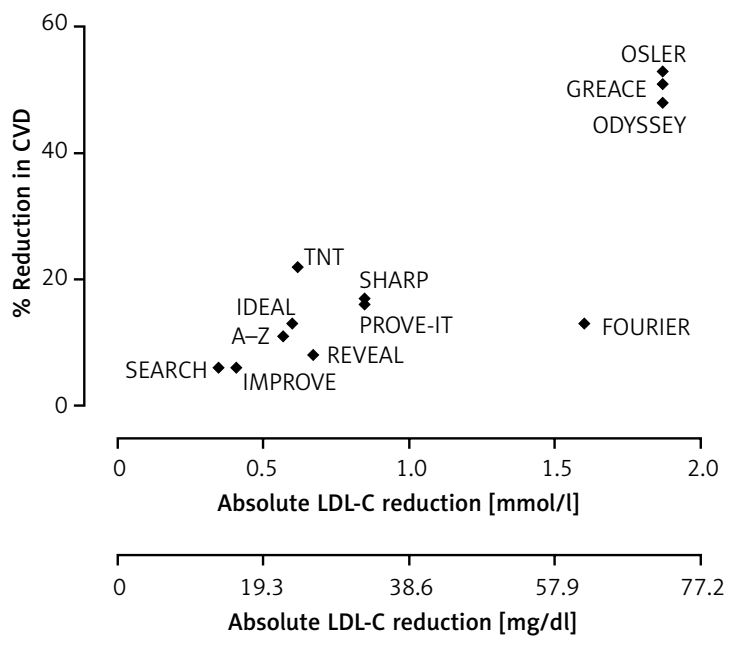

Figure 2. Association between cardiovascular risk reduction and absolute reduction in low density lipoprotein cholesterol in major randomised control trials [67, 75, 81, 82, 85]. Adapted from Soran et al. [75] (where full list of additional individual trial references can be found). There is a consistent reduction in cardiovascular risk of about one-fifth for every $1 \mathrm{mmol} / \mathrm{l}(38 \mathrm{mg} / \mathrm{dl}$ ) reduction in LDL-C

CVD - cardiovascular disease, LDL-C - low density lipoprotein cholesterol. OSLER - Open Label Study of Long Term Evaluation Against LDL-C, GREACE - Greek Atorvastatin and Coronary Heart Disease Evaluation, ODYSSEY - Efficacy and Safety of Alirocumab in Reducing Lipids and Cardiovascular Events, FOURIER - Further Cardiovascular Outcomes Research with PCSK9 Inhibition in Subjects with Elevated Risk, TNT - Treating to New Targets, SHARP - Study of Heart and Renal Protection, PROVE-IT - Pravastatin or Atorvastatin Evaluation and Infection Therapy, IDEAL - Incremental Decrease in End Points Through Aggressive Lipid Lowering, A-Z Aggrasat-Zocar Phase, REVEAL - Randomized Evaluation of the Effects of Anacetrapib through Lipid Modification, IMPROVE - Improved Reduction of Outcomes: Vytorin Efficacy International Trial, SEARCH - Study of Effectiveness of Additional Reductions in Cholesterol and Homocysteine. 
However, reassuringly, the EBBINGHAUS (Evaluating PCSK9 Binding Antibody Influence on Cognitive Health in High Cardiovascular Risk Subjects) study which specifically assessed neuro-cognition in 1974 patients from the FOURIER cohort using the Cambridge Neuropsychological Test Automated Battery (CANTAB) tool did not find that LDL-C levels lower than $0.65 \mathrm{mmol} / \mathrm{l}(25 \mathrm{mg} / \mathrm{dl})$ were associated with neurocognitive impairment [89]. Importantly, in the IMPROVE-IT trial there was no increase in adverse events in those receiving intensive treatment compared to the control group [81]. Robinson et al. have published a pooled analysis of all phase 2 and 3 trials of alirocumab which included 14 trials ( $n=3440$ with up to 2 years of follow-up) with a specific focus on patients who achieved very low LDL-C levels of $<0.65 \mathrm{mmol} / \mathrm{l}(25 \mathrm{mg} / \mathrm{dl}, n=839)$ as well as those participants with on-treatment LDL-C $<0.39 \mathrm{mmol} / \mathrm{l}$ (15 mg/dl, $n=314)$ [90]. Although the studies were limited by a short treatment duration (median duration was 78 weeks), reassuringly, there were no significant increases in the incidence of diabetes, musculoskeletal complaints or neurocognitive events when LDL-C levels fell below 0.65 $\mathrm{mmol} / \mathrm{l}$ [90]. There was, however, a statistically significant increase in cataract formation $(H R=3.40$; 95\% confidence interval (Cl): $1.58-7.35)$ in those who achieved an LDL-C of $<0.65 \mathrm{mmol} / \mathrm{l}(25 \mathrm{mg} / \mathrm{dl})$ compared to those with an achieved LDL-C $>0.65$ $\mathrm{mmol} / \mathrm{l}(25 \mathrm{mg} / \mathrm{dl})$ [90]. The mechanisms behind this observation are yet to be fully elucidated [90]. Similarly, in the REVEAL trial a further reduction in $\mathrm{LDL}-\mathrm{C}$ to a mean of $0.98 \mathrm{mmol} / \mathrm{l}(38 \mathrm{mg} / \mathrm{dl})$ was not associated with an increase in adverse events [85].

In addition, a Mendelian Randomisation study conducted in a Danish population ( $n=111,194)$ did not find a causal link between developing dementia and having low LDL-C levels (resulting from genetic variants of the PCKS9 and HMCGR genes) [91]. The authors reported a lower risk of Alzheimer's dementia with lower LDL-C levels, but an increase in Parkinson's disease with an adjusted hazard ratio of 1.70 (95\% Cl: 1.03-2.79) [91].

There is gathering evidence that lower LDL-C levels than have been traditionally championed may have a significant impact on CVD-related mortality, in particular in high-risk patients and/ or those with the highest pre-treatment LDL-C [75, $76,92]$. As a result, clinical guidelines of LDL-C targets may change which will affect the threshold at which to start lipid modifying treatment when considering that the Number Needed to Treat (NNT) to achieve benefit depends on the absolute reduction in LDL-C $[75,76,92,93]$.

\section{Which method for CVD risk assessment?}

There is general agreement that the threshold of absolute CVD risk at which statin treatment is started should be cost-effective. However, current recommendations for the translation of models of cost effectiveness into practice are not sufficiently robust to be robotically followed.

\section{Does the level of LDL cholesterol matter?}

The assumption that the same benefit will accrue at similar levels of risk, regardless of the LDL cholesterol, is mistaken. It stems from a misunderstanding of the findings of the Cholesterol Treatment Trials (CTT) meta-analysis which clearly showed that for each $1 \mathrm{mmol} / \mathrm{l}(38 \mathrm{mg} / \mathrm{dl})$ decrease in LDL cholesterol achieved with statin treatment there was a linear 22\% decrease in relative CVD risk relative to similar controls (usually placebo-treated) $[20,21,55]$. This does not mean that the number of events prevented is the same in all patients with the same absolute risk. That number is dependent not only on the absolute risk, but also the LDL-C level. If the LDL-C is $3 \mathrm{mmol} / \mathrm{l}$ (116 $\mathrm{mg} / \mathrm{dl})$ then achieving a target of $2 \mathrm{mmol} / \mathrm{l}(77 \mathrm{mg} /$ dl) will decrease risk by $22 \%$, but, if it is $5 \mathrm{mmol} / \mathrm{l}$ $(193 \mathrm{mg} / \mathrm{dl})$, then reaching the goal of $2 \mathrm{mmol} / \mathrm{l}$ $(77 \mathrm{mg} / \mathrm{dl})$ would be expected to reduce risk by $66 \%$. Thus, treating people at 10\% 10-year CVD risk with an LDL-C of $5 \mathrm{mmol} / \mathrm{l}(193 \mathrm{mg} / \mathrm{dl})$ will actually prevent more events than treating people at $20 \%$ risk with an LDL-C of $3 \mathrm{mmol} / \mathrm{l}(116 \mathrm{mg} / \mathrm{dl})$ [93]. Therefore, the pre-treatment LDL-C should play a more important role when clinicians decide when to start treatment for primary prevention rather than basing this decision purely on CVD risk [92]. The US recommendations recognise this by advocating lipid-lowering medication at lower levels of risk in people with higher LDL-C [57]. It also has a bearing on the choice of risk assessment method. There is a limit to the proportion of risk, which can be explained by a predictive model (multiple $R^{2}$ ). Most of the explicable risk will be explained by six risk factors: gender, age, smoking, lipids, diabetes and blood pressure. The incorporation of other risk factors, although superficially attractive, because it may allow a little additional risk to be predicted, has the disadvantage that it reduces the proportion of risk attributed to the 6 fundamental risk factors, particularly those which have a degree of inaccuracy, biological variation or uncertainty in their ascertainment, namely smoking, lipids and blood pressure. Ironically these three are the mutable risk factors that we are able to modify therapeutically with anti-smoking strategies, statins and antihypertensive drugs. Thus, identifying a group of people as at high risk who do not smoke or have particularly high blood pressure or LDL cholesterol for intervention may lead to a smaller NNT to prevent a CVD event than treating people at lower risk, but in whom smoking is over-represented or whose blood pressure 
or LDL cholesterol is more clearly elevated [94]. The only comparison of international guidelines thus far which takes into account both population impact and cost-effectiveness showed that the JBS recommendations based on a modified Framingham equation similar to that originally advocated by NICE were superior to European and North American ones [64]. The official advice to use a method based on QRISK2 therefore requires careful reflection. Furthermore, it has been argued that epidemiology may have under-estimated LDL-C as a risk factor for CVD [95-97]. This is partly because of regression dilution bias resulting from making only single measurements.

\section{Should socio-economic status be used in individual CVD risk assessment?}

Both the QRISK2 and ASSIGN algorithms include postcode as an indicator of social deprivation. This introduces an essentially immutable risk factor and decreases the proportion of risk attributed to smoking, lipids and blood pressure. Furthermore, although it is established that lower socio-economic status is associated with increased CVD incidence [98], which indicates that some special measures need to be adopted to improve health services in socially deprived communities, there has never been public debate about whether decreasing the likelihood that people in higher socio-economic groupings receive statins will improve the effectiveness of CVD risk reduction in the community as a whole. It is noteworthy in this context that the cost of simvastatin $40 \mathrm{mg}$ and many antihypertensive drugs to the NHS now greatly exceeds the prescription charges paid by the financially able as opposed to poorer people. There thus does not even seem to be an economic argument for making postcodes arbiters of who should receive statin or antihypertensive treatment.

\section{How to adjust CVD risk for adverse family history and ethnic background}

It is generally recommended to adjust calculated risk for people with an adverse family history and/or those who originate or have antecedents from the Indian subcontinent [26]. This adjustment is sometimes viewed as recognition that such people have some unknown additional risks factor which is independent of the lipids, smoking, $\mathrm{BP}$ and DM, whereas it is just as likely that these known risk factors are more likely to have early clinical consequences if left unchecked. Adjustment for them may therefore be best done after risk based on these other risk factors has been calculated. Indeed, current European guidance promotes more intensive interventions in those with a family history of CVD compared to those without such a history when a person is on the fringe of the treatment threshold [73]. We do not condone the practice of imposing greater restriction in the prescription of statins and antihypertensive agents to people of Afro-Caribbean origin, which is a feature of QRISK2. They may have a lower risk of atherosclerotic CVD, but their risk of stroke is increased [99].

\section{Over how long a time period should CVD risk be estimated - 10 years or life?}

People at high lifetime risk may not be treated at a young enough age to avoid preventable premature death and morbidity if a single threshold is used regardless of age. Box 7 illustrates this. This problem could be overcome by having lower absolute risk thresholds for younger people. No recommendations currently do this. The European advice was, however, that in deciding whether to treat young people with adverse reversible risk factors earlier than dictated by their current absolute risk, risk should be calculated as if the patient was already aged 60 years. The problem with this is that abnormalities of lipids and blood pressure tend to get worse with age, and this is not taken into account. The degree of risk relative to people of the same age and gender can be calculated using the Dundee risk equation [100] and this can be helpful in avoiding treating too many younger people, if, for example only those at greater than the $95^{\text {th }}$ percentile of risk are considered. This approach was incorporated in the cardiovascular risk assessor (CVRA) programme published with JBS2 [101]. JBS3 now offers lifetime risk estimation as an aid to the clinician, but this is likely to include

Box 7. Thirty three additional CVD events are prevented by the age of 60 years if statin treatment was initiated in 1000 people aged 40 years when their 10-year CVD risk was 10\% as opposed to waiting until they were aged 50 years and had a $20 \% 10$-year risk

\begin{tabular}{|cccccc|}
\hline Age [year] & $\begin{array}{c}10-\text { CVD } \\
\text { risk }\end{array}$ & $\begin{array}{c}\text { Mean annual CVD } \\
\text { risk until age } 60\end{array}$ & $\begin{array}{c}\text { CVD events/1000 } \\
\text { by age } 60\end{array}$ & $\begin{array}{c}\text { CVD events/ } \\
1000 \text { prevented by } \\
\text { statin* by age } 60\end{array}$ & $\begin{array}{c}\text { NNT for } 10 \text { years to } \\
\text { prevent one event }\end{array}$ \\
\hline 40 & $10 \%$ & $1.5 \%$ & 300 & 100 & 20 \\
\hline 50 & $20 \%$ & $2.0 \%$ & 200 & 67 & 15 \\
\hline
\end{tabular}

${ }^{\star}$ Assumes statin decreases risk by one third. 
H. Soran, S. Adam, J.B. Mohammad, J.H. Ho, J.D. Schofield, S. Kwok, T. Siahmansur, Y. Liu, A.A. Syed, S.S. Dhage, C. Stefanutti, R. Donn, R.A. Malik, M. Banach, P.N. Durrington

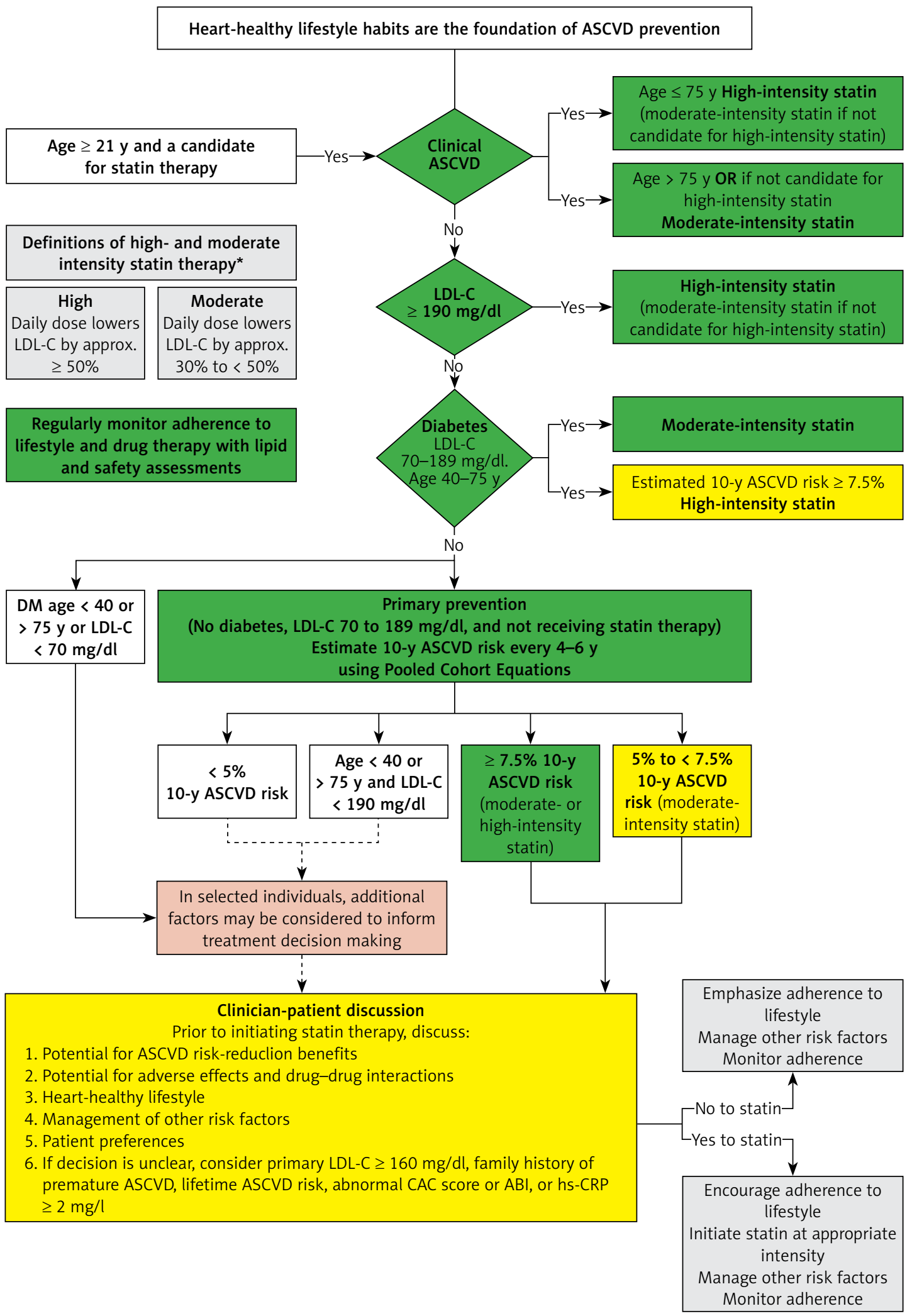

Figure 3. Summary of 2013 ACC/AHA guideline on the treatment of blood cholesterol to reduce atherosclerotic cardiovascular risk in adults: a report of the American College of Cardiology/American Heart Association Task Force on Practice Guidelines (modified according [57]) 
not simply projected CVD mortality, but also competing causes of death, which introduces many unresolved anomalies. For example, smoking cessation may reduce the likelihood of someone dying of another smoking-related condition and therefore allow for a greater possibility for death to be eventually caused by CVD despite one of the CVD risk factors being addressed [35]. A recent study has questioned whether there is any advantage in using lifetime risk as an arbiter of who should receive statin treatment [102]. Some have questioned the wisdom of estimating individual risk at all and proposed that everyone beyond a certain age should be offered statin treatment [103]. This would, however, still not overcome the problem of who to treat earlier in life.

\section{The bottom line on CVD risk assessment using multiple risk factors}

An article of this length does not permit full discussion of the merits or otherwise of the risk engines available, but only to correct certain misapprehensions about existing ones in a rapidly developing field. A method should be used which will have the greatest population impact [104]. This is not solely dependent on accuracy, although it would be better if that was achieved. It is of paramount importance that a method identifies people who stand to gain most from giving up smoking and receiving statin and/or antihypertensive treatment, which is a reason for not using QRISK2. In our view, the best methods for use with British guidelines remain the modified Framingham method in the British National Formulary and the Scottish ASSIGN method (the Scottish postcode is easily omitted from this). An ASSIGN score of 20 is equivalent to a CVD risk of $20 \%$ over the next 10 years and, as is the case for a similar risk estimated by the JBS modified Framingham method, is an indication for a statin if the LDL cholesterol is $\geq 2 \mathrm{mmol} / / \mathrm{l}(77 \mathrm{mg} / \mathrm{dl})$. There is, however, no reason in the UK not to adopt the European SCORE method. With SCORE a 5\% 10-year risk of fatal CVD is an indication for statin therapy if LDL cholesterol is $\geq 2.5 \mathrm{mmol} / \mathrm{l}(97 \mathrm{mg} / \mathrm{dl})$ and a $10 \%$ 10 -year risk of fatal CVD is an indication if LDL cholesterol is $\geq 1.8 \mathrm{mmol} / \mathrm{l}(70 \mathrm{mg} / \mathrm{dl})$.

\section{A summary of treatment recommendations}

These are summarised in Figures 3-5. The strength of evidence for the clinical management of hypercholesterolaemia is shown in Box 8 .

There have been no trials to assess the relative effect of the various guidelines used in conjunction with their recommended risk engines in decreasing CVD incidence [105], which means that comparison is necessarily speculative. One simulation by Manuel et al. appeared to show that the JBS guidelines were superior [64], but may not have adequately taken into account the greater reduction in CVD events when higher LDL cholesterol levels are successfully lowered with more potent statins (see earlier discussion). The USA recommendations rely much more on LDL cholesterol than others. The least influenced by LDL cholesterol would be the NICE recommendations, with no LDL therapeutic goal combined with QRISK2 which is relatively insensitive to LDL cholesterol as a component of risk. JBS with risk calculated using the modified Framingham or ASSIGN risk equations or the European guidelines combined with SCORE would seem a practical compromise.

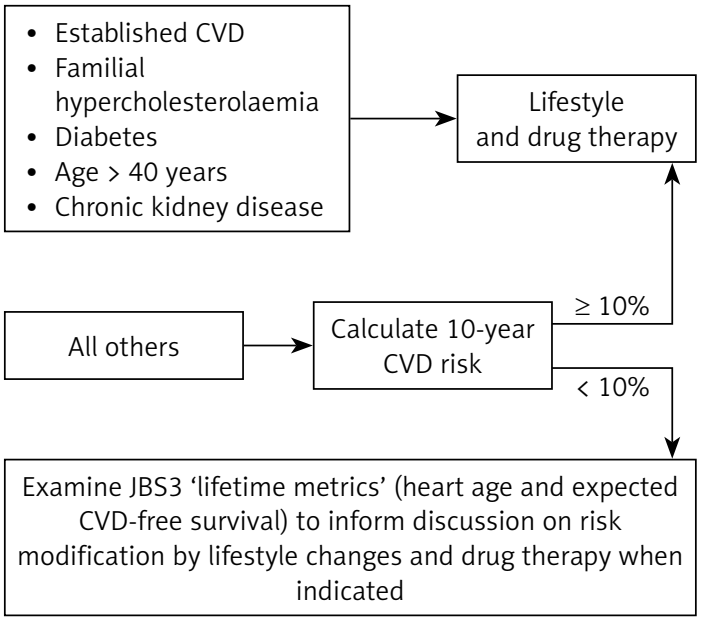

Figure 4. Summary of Joint British Societies' guideline 3 (modified according [35])

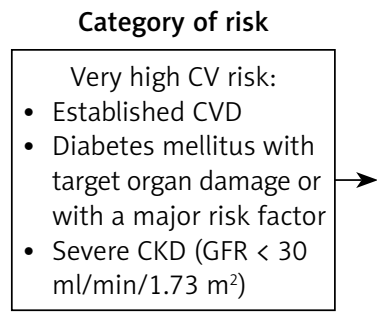

Treatment (initiation and goal)

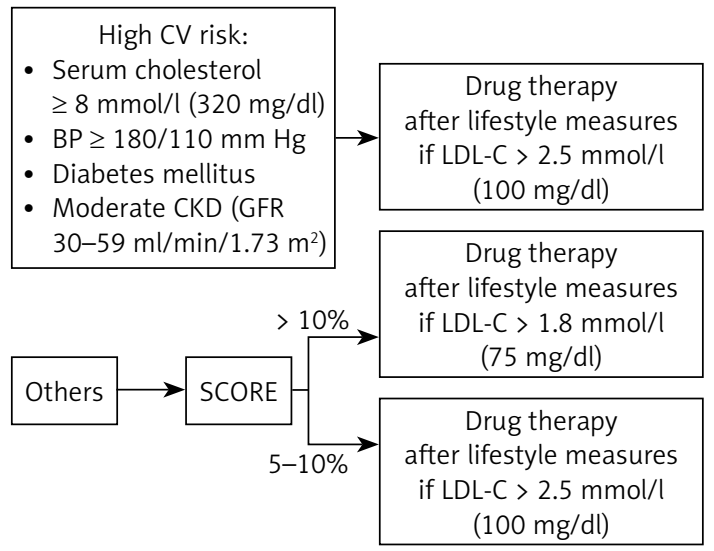

Figure 5. Summary of European Atherosclerosis Society guideline 2016 (modified according [34]) 
H. Soran, S. Adam, J.B. Mohammad, J.H. Ho, J.D. Schofield, S. Kwok, T. Siahmansur, Y. Liu, A.A. Syed, S.S. Dhage, C. Stefanutti, R. Donn, R.A. Malik, M. Banach, P.N. Durrington

Box 8. Summary points and level of evidence in the management of dyslipidaemia

\begin{tabular}{|c|c|}
\hline Action & Level of evidence \\
\hline \multicolumn{2}{|l|}{ Lipids should be measured regardless of age in: } \\
\hline Established atherosclerotic CVD* & IA \\
\hline T2/T1 diabetes & IA \\
\hline Hypertension & IB \\
\hline $\begin{array}{l}\text { Family history of atherosclerotic CVD before 50years of age in male relative(s) or before } 60 \text { in } \\
\text { female relative(s) }\end{array}$ & IC \\
\hline CKD & IC \\
\hline $\begin{array}{l}\text { Children and adults suspected of having familial hypercholesterolaemia (FH) because of } \\
\text { physical signs, family history of CVD or particularly high cholesterol }\end{array}$ & IC \\
\hline $\begin{array}{l}\text { Lipids should be measured in all men and women aged } \geq 40 \text { years as part of an assessment } \\
\text { of CVD risk }\end{array}$ & IIC \\
\hline TC: HDL-C is recommended for screening & IA \\
\hline $\begin{array}{l}\text { LDL-C should be measured before initiating lipid-lowering medication, for dose titration and as } \\
\text { the goal of treatment }\end{array}$ & IA \\
\hline Non-HDL-C or apoB should be considered as a replacement for LDL-C in hypertriglyceridaemia & IB \\
\hline \multicolumn{2}{|l|}{$\begin{array}{l}\text { Initiate lipid-lowering with a statin (at the licenced starting dose), if LDL-C } \geq 1.8 \mathrm{mmol} / \mathrm{l} \\
(70 \mathrm{mg} / \mathrm{dl} \text { ) and there is no contraindication e.g. untreated hypothyroidism in high-risk patients } \\
\text { (established atherosclerotic CVD, }\end{array}$} \\
\hline $\begin{array}{l}\text { T1/2 diabetes aged } \geq 40 \text { years }{ }^{\dagger} \text {, people with familial hypercholesterolaemia or whose TC } \geq 8 \mathrm{mmol} / \mathrm{l} \\
(309 \mathrm{mg} / \mathrm{dl}) \text {, estimated CVD risk } \geq 10 \% \text { over } 10 \text { years } \mathrm{s}^{+1}\end{array}$ & IA \\
\hline $\begin{array}{l}\text { Choose a statin, which titrated up, if necessary, can achieve the LDL goal. If unable to achieve } \\
\text { targets with statins OR if patient intolerant to statins, consider using non-statin therapy } \\
\text { including PCSK9 inhibitors and ezetimibe }\end{array}$ & IA \\
\hline LDL-C goal is $<1.8 \mathrm{mmol} / \mathrm{l}(70 \mathrm{mg} / \mathrm{dl})$ (non-HDL-C $<2.6 \mathrm{mmol} / \mathrm{l}[101 \mathrm{mg} / \mathrm{dl}]$, apoB $<80 \mathrm{mg} / \mathrm{dl})$ & IA \\
\hline All patients should receive advice about diet and exercise & IA \\
\hline $\begin{array}{l}\text { Women in whom pregnancy is possible and all patients suspected of having FH should be } \\
\text { referred to a Lipid Clinic. Lipid Clinic referral should also be considered in patients who seem to } \\
\text { be multiply statin intolerant and who do not achieve their LDL goal, despite use of a potent statin }\end{array}$ & IC \\
\hline
\end{tabular}

${ }^{\star} \mathrm{CHD}$ (previous MI, stable or unstable angina), stroke, TIA, peripheral arterial disease; ${ }^{* *}$ the risk assessment method intended for use with local guidelines should generally be employed e.g. NICE modified Framingham or ASSIGN with JBS2, SCORE with the European recommendations and ATPIII version of Framingham in USA; ${ }^{\dagger}$ oounger if additional risk factor such as microalbuminuria; ${ }^{+1}$ or equivalent risk with ATPIII version of Framingham or SCORE.

\section{Secondary hyperlipidaemia}

Maintenance of LDL cholesterol at $<2 \mathrm{mmol} / /$ $(77 \mathrm{mg} / \mathrm{dl})$ is a target of treatment in both type 1 and 2 diabetes. Both types are also associated with hypertriglyceridaemia (see earlier discussion of type 2 as more properly a primary disorder of lipid metabolism). In type I diabetes insulin treatment tends to restore triglycerides to normal and frequently HDL cholesterol levels are high when glycaemic control is good. In both types of diabetes, nephropathy is associated with increased LDL cholesterol and triglycerides and decreased HDL cholesterol [106]. Hypertriglyceridaemia is also caused by high alcohol consumption, chronic renal insufficiency and parenchymal liver disease. It is also a cause of non-alcoholic steatohepatitis. Gout and hyperuricaemia frequently accompany hypertriglyceridaemia. Hypothyroidism can cause both hypercholesterolaemia and hypertriglycer- idaemia. Obstructive liver disease and nephrotic syndrome cause hypercholesterolaemia. When obstructive liver disease coexists with parenchymal disease and when nephrotic syndrome is associated with decreased GFR, mixed hyperlipidaemia often occurs.

\section{Lipid modification therapy}

\section{Statins}

Statins reduce cholesterol synthesis in the liver by competitively inhibiting 3-hydroxy-methylglutaryl coenzyme A reductase (HMG-CoA reductase) thus depleting hepatic cholesterol (Figure 1). This upregulates hepatic LDL receptor expression and increases clearance of LDL from blood. Statins vary in their cholesterol-lowering potency $[97,107,108]$ (Figure 6). Statins substantially reduce cardiovascular morbidity and mortality in primary and second- 
ary prevention $[20,21,40,109]$. This effect is considered to be mostly secondary to LDL cholesterol reduction [109-111]. There is increasing evidence to support the wider use of statins [54]. Statins should be viewed as a means of CVD prevention regardless of the source of the excess risk. In general, statins are safe and well tolerated, but $80 \mathrm{mg}$ simvastatin daily is associated with an unacceptably high risk of statin-induced myopathy [112]. Statin associated muscle symptoms (SAMS)/statin intolerance might exist in $\sim 15-20 \%$, but complete statin intolerance associated with the discontinuation of statin therapy occurs in less than 5\% $[113,114]$. The risk of myositis is lower with lower doses and does not relate to the degree of LDL cholesterol lowering. Generally the excess risk of myopathy compared with placebo in statin RCTs is less than 1 in 10000 patients treated with statins [115]. Muscle-aching and minor elevations of creatine kinase (CK) are common regardless of statin treatment, but are more frequently ascribed to it in clinical practice than is the case in placebo-controlled trials.

\section{Ezetimibe}

Ezetimibe is generally well tolerated, but is a less effective LDL cholesterol-lowering agent than statins (usually 10-15\%) [116]. It acts by inhibiting intestinal dietary and biliary cholesterol absorption (Figure 1) by binding to the Niemann-Pick C1-like 1 receptor. NICE guidance as well as recent European Society of Cardiology (ESC)/European Atherosclerosis Society (EAS) guidelines suggest using ezetimibe as an adjunct to statin therapy in patients with particularly high LDL-C levels and in high-risk patients who are truly statin intolerant [54, 117]. There has been one RCT demonstrating a decrease in CVD incidence with ezetimibe and that was against a background of simvastatin therapy in chronic renal failure [118]. In addition, using ezetimibe in conjunction with simvastatin was shown to significantly reduce CV events and therefore identified additional benefit with intensive LDL-C lowering using ezetimibe $[81,119]$.

\section{Bile acid sequestrating agents}

These impede the reabsorption of bile acids from the terminal ileum thereby increasing the hepatic requirement for cholesterol as a precursor for the synthesis of bile acids to replenish the enterohepatic pool (Figure 1). The increased hepatic cholesterol requirement is partially met by increased LDL receptor expression thereby lowering circulating LDL. Even at doses insufficient to lower LDL to the extent that can be achieved by statin therapy, they are poorly tolerated, but they can decrease CVD risk [120]. Unfortunately, they are not available in most European countries.

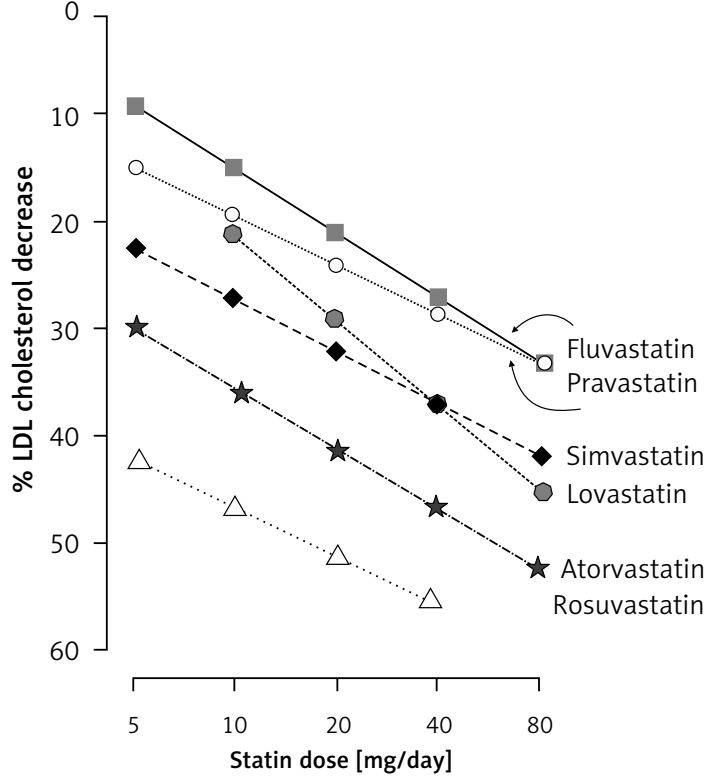

Figure 6. Statins and their LDL cholesterol-lowering potency (Handrean Soran \& Paul Durrington 2008)

\section{Lipid lowering nutraceuticals}

There has been recent interest in a possible role of nutraceuticals and functional foods as an adjunct to lipid lowering therapy, though their efficacy and safety remain poorly understood [121].

\section{Other lipid-lowering drugs}

Fibrate drugs and nicotinic acid were presumed to confer benefit because they lower triglycerides and raise HDL cholesterol. However, recent clinical trial evidence does not support their use to lower CVD risk [122-125]. Purified omega-3 fatty acids can decrease triglycerides [53] and decreased CVD risk in some studies [126]. It should be remembered that they contribute to chylomicron formation and are readily oxidisable. Unrefined fish oil has not been shown to confer benefit in meta-analyses. PCSK9 inhibitors [127] have recently been licensed in the UK but they are only to be used in patients with extremely high CVD risk as specified by NICE [128, 129]. The CETP inhibitor Anacetrapib may reduce CVD risk as reported in the REVEAL trial [85].

\section{Surgery, liver transplantation and extracorporeal LDL removal}

Ileal bypass, a procedure now rarely considered, effectively reduces LDL-C and lowers CHD mortality by $35 \%$ [130]. Liver transplantation has been used in homozygous $\mathrm{FH}$ patients to provide the functional hepatic LDL receptors that these patients lack [131]. Bariatric surgery has also been shown to be effective at reducing LDL-C in obese patients. A recent meta-analysis (48 studies, 6077 partic- 
ipants) showed a significant reduction in LDL-C by 1-month post-operatively (standardised mean difference $-0.92,95 \% \mathrm{Cl}:-1.31$ to -0.52 ) with the effect being maintained in the longer-term [132]. Indeed, in addition to improvements in the lipid profile, bariatric surgery induced weight loss is also associated with significant improvements in systemic inflammation, insulin resistance, mediators of vascular inflammation, vascular function, perivascular adipose tissue inflammation and adipose tissue anticontractile properties [133-135]. Interestingly, obesity complicated by obstructive sleep apnoea (OSA) is associated with a more pronounced impairment of $\mathrm{HDL}$ function, systemic and adipose tissue inflammation [136]. Given the marked improvement seen in OSA itself after bariatric surgery [134, 137, 138], it may also improve the associated lipoprotein and inflammatory disturbance.

Where available, for patients with homozygous $\mathrm{FH}$ and severe HeFH, lipoprotein apheresis may be a preferable treatment option, reducing mean LDL-C by more than $50 \%$ and also reducing mortality $[139,140]$. However, criteria for lipoprotein apheresis eligibility and the percentage of patients receiving treatment vary widely from country to country and access to this procedure remains limited because of its relatively high cost and low availability. After ODYSSEY ESCAPE results, close to two-thirds of all patients on apheresis might be effectively treated with PCSK9 inhibitors [141143]. However, lipoprotein apheresis will still be required for many patients with homozygous $\mathrm{FH}$ and the most severe cases of heterozygous $\mathrm{FH}$ [142-144]. Lomitapide is a small molecule inhibitor of microsomal triglyceride transfer protein. It reduces the hepatic assembly of very low-density lipoprotein (VLDL) and intestinal chylomicrons and consequently reduces LDL-C production, an action independent of LDLR activity. Lomitapide is a highcost drug licensed for patients with homozygous $\mathrm{FH}[144,145]$. It reduces the hepatic assembly of VLDL and intestinal chylomicrons consequently reducing $L D L-C$ production, an action independent of LDLR activity $[144,145]$. Mipomersen, a second-generation antisense oligonucleotide, which inhibits hepatic APOB synthesis has a similar effect [146] but is not licensed by the EMA.

\section{Agents in development}

Infusion of HDL mimetic peptides is also currently being investigated [147-149]. Improving the functionality of HDL may be more important than increasing HDL cholesterol [8]. Gene therapy, supplying the normal LDL receptor gene via a plasmid is also a potential future treatment [150]. Additionally, RVX-208, which has been shown to improve the particle profile of $\mathrm{HDL}$ to favour one which promotes RCT, has shown encouraging early results in potentially preventing and treating atherosclerosis [151, 152]. In a phase 2 trial, a synthetic small interfering RNA directed against PCSK9 was shown both to reduce PCSK9 and LDL-C levels [153]. Additionally, another novel agent, bempedoic acid, inhibits ATP citrate lyase $(A C L)$, an enzyme involved in fatty acid and cholesterol synthesis, predominantly in the liver and white adipose tissue and has been shown to reduce LDL-C in several phase 2 trials [154].

\section{Conflict of interest}

Handrean Soran received research grants from Alexion, AMGEN, AKCEA, Pfizer, MSD, Genzyme-Sanofi \& received personal fees and education grants from Aegerion, Amgen, Janssen Cilag Ltd, Lilly, MSD, Pfizer, Sanofi, NAPP, Link-Medical, Alexion.

Maciej Banach - speakers bureau: Abbott/ Mylan, Abbott Vascular, Actavis, Akcea, Amgen, KRKA, MSD, Sanofi-Aventis and Valeant; consultant to Abbott Vascular, Akcea, Amgen, Daichii Sankyo, Esperion, Lilly, MSD, Pfizer, Resverlogix, Sanofi-Aventis.

\section{References}

1. World Health Organisation. Global Health Observatory (GHO) Data: Raised Cholesterol. Available from: http:// www.who.int/gho/ncd/risk_factors/cholesterol_text/en/.

2. Durrington PN. Hyperlipidaemia. Diagnosis and Management. $3^{\text {rd }}$ ed. Hodder Arnold, London 2007.

3. Charlton-Menys V, Durrington PN. Human cholesterol metabolism and therapeutic molecules. Exp Physiol 2008; 93: 27-42.

4. Bhatnagar D, Soran H, Durrington PN. Hypercholesterolaemia and its management. BMJ 2008; 337: a993.

5. Charlton-Menys V, Durrington P. Apolipoproteins Al and B as therapeutic targets. J Intern Med 2006; 259: 462-72.

6. Franssen R, Monajemi H, Stroes ES, Kastelein JJ. Obesity and dyslipidemia. Med Clin North Am 2011; 95 : 893-902.

7. National Institute for Health and Clinical Excellence (NICE). Familial hypercholesterolaemia: identification and management. NICE Clinical Guidance 71. London: NICE; 2008. Available from: https://www.nice.org.uk/ guidance/CG71.

8. Soran H, Hama S, Yadav R, Durrington PN. HDL functionality. Curr Opin Lipidol 2012; 23: 353-66.

9. Otocka-Kmiecik A, Mikhailidis DP, Nicholls SJ, Davidson M, Rysz J, Banach M. Dysfunctional HDL: a novel important diagnostic and therapeutic target in cardiovascular disease? Prog Lipid Res 2012; 51: 314-24.

10. Rysz-Gorzynska M, Banach M. Subfractions of highdensity lipoprotein (HDL) and dysfunctional HDL in chronic kidney disease patients. Arch Med Sci 2016; 12: 844-9.

11. Rosenson RS, Brewer HB Jr, Davidson WS, et al. Cholesterol efflux and atheroprotection: advancing the concept of reverse cholesterol transport. Circulation 2012; 125: 1905-19. 
12. BHF CVD STATISTICS COMPENDIUM 2017 [Internet]. BHF. 2017. Available from: https://www.bhf.org.uk/ research/heart-statistics/heart-statistics-publications/ cardiovascular-disease-statistics-2017.

13. Chen Z, Peto R, Collins R, MacMahon S, Lu J, Li W. Serum cholesterol concentration and coronary heart disease in population with low cholesterol concentrations. BMJ 1991; 303: 276-82.

14. Iso $\mathrm{H}$. Changes in coronary heart disease risk among Japanese. Circulation 2008; 118: 2725-9.

15. Liu X, Mai J, Rao X, et al. Adverse trends of cardiovascular risk factors among low risk populations (19831994): a cohort study of workers and farmers in Guangzhou, China. BMC Public Health 2011; 11: 931.

16. Chaudhury M. Blood analytes. In: Health Survey for England 2003 Risk factors for cardiovascular disease. 2. Sproston K, Primatesta P (eds.). The Stationery Office, London 2004; 241-87.

17. Banach M, Wojtowicz E, Tomaszewski M, et al. P5306 The comparison of the lipid profile in the population of Poland between 2004, 2006 and 2015 based on the results of the LIPIDOGRAM cohort studies. Eur Heart J 2017; 38 (Suppl 1): ehx493.P5306-ehx493.

18. Robertson TL, Kato H, Gordon T, et al. Epidemiologic studies of coronary heart disease and stroke in Japanese men living in Japan, Hawaii and California. Coronary heart disease risk factors in Japan and Hawaii. Am J Cardiol 1977; 39: 244-9.

19. Patel JV, Vyas A, Cruickshank JK, et al. Impact of migration on coronary heart disease risk factors: comparison of Gujaratis in Britain and their contemporaries in villages of origin in India. Atherosclerosis 2006; 185: 297-306.

20. Cholesterol Treatment Trialists C, Kearney PM, Blackwell $L$, Collins R, et al. Efficacy of cholesterol-lowering therapy in 18,686 people with diabetes in 14 randomised trials of statins: a meta-analysis. Lancet 2008; 371: 117-25.

21. Cholesterol Treatment Trialists C, Baigent C, Blackwell L, Emberson J, et al. Efficacy and safety of more intensive lowering of LDL cholesterol: a meta-analysis of data from 170,000 participants in 26 randomised trials. Lancet 2010; 376: 1670-81.

22. Miller M, Stone NJ, Ballantyne C, et al. Triglycerides and cardiovascular disease: a scientific statement from the American Heart Association. Circulation 2011; 123: 2292-333.

23. Alberti KG, Eckel RH, Grundy SM, et al. Harmonizing the metabolic syndrome: a joint interim statement of the International Diabetes Federation Task Force on Epidemiology and Prevention; National Heart, Lung, and Blood Institute; American Heart Association; World Heart Federation; International Atherosclerosis Society; and International Association for the Study of Obesity. Circulation 2009; 120: 1640-5.

24. Rubenfire M, Brook RD. HDL cholesterol and cardiovascular outcomes: what is the evidence? Curr Cardiol Rep 2013; 15: 349.

25. Jacobson TA, Ito MK, Maki KC, et al. National Lipid Association recommendations for patient-centered management of dyslipidemia: part 1 - executive summary. J Clin Lipidol 2014; 8: 473-88.

26. National Institute for Health and Clinical Excellence (NICE). Cardiovascular disease: risk assessment and reduction, including lipid modification. Clinical guideline [CG181]. London: NICE; 2014 (Updated Sep 2016). Available from: https://www.nice.org.uk/guidance/cg181.

27. Blaha MJ, Blumenthal RS, Brinton EA, Jacobson TA, National Lipid Association Taskforce on Non HDLC. The importance of non-HDL cholesterol reporting in lipid management. J Clin Lipidol 2008; 2: 267-73.

28. Stephen AM, Sieber GM. Trends in individual fat consumption in the UK 1900-1985. Br J Nutr 1994; 71: 775-88.

29. Bansal N, Cruickshank JK, McElduff P, Durrington PN. Cord blood lipoproteins and prenatal influences. Curr Opin Lipidol 2005; 16: 400-8.

30. McGill HC Jr, McMahan CA, Herderick EE, Malcom GT, Tracy RE, Strong JP. Origin of atherosclerosis in childhood and adolescence. Am J Clin Nutr 2000; 72 (5 Suppl): 1307S-15S.

31. Rader DJ, Cohen J, Hobbs HH. Monogenic hypercholesterolemia: new insights in pathogenesis and treatment. J Clin Invest 2003; 111: 1795-803.

32. Elder SJ, Lichtenstein AH, Pittas AG, et al. Genetic and environmental influences on factors associated with cardiovascular disease and the metabolic syndrome. J Lipid Res 2009; 50: 1917-26.

33. Kotowski IK, Pertsemlidis A, Luke A, et al. A spectrum of PCSK9 alleles contributes to plasma levels of low-density lipoprotein cholesterol. Am J Hum Genet 2006; 78: 410-22

34. Catapano AL, Graham I, De Backer G, et al. 2016 ESC/ EAS Guidelines for the management of dyslipidaemias. Eur Heart J 2016; 37: 2999-3058.

35. Board JBS. Joint British Societies' consensus recommendations for the prevention of cardiovascular disease (JBS3). Heart 2014; 100 Suppl 2: ii1-67.

36. Durrington P. Dyslipidaemia. Lancet 2003; 362: 717-31.

37. Brown MS, Hobbs HH, Goldstein JL. Familial hypercholesterolaemia. In: The Metabolic and Molecular Bases of Inherited Disease (OMMBID). $8^{\text {th }}$ ed. Scriver CR, Beaudet AL, Sly WS, Valle D (eds). McGraw-Hill; New York 2000; 2863-91.

38. Brunzell JD, Deeb SS. Familial lipoprotein lipase deficiency, apo C-II deficiency and hepatic lipase deficiency. In: The Metabolic and Molecular Bases of Inhertied Disease. $8^{\text {th }}$ ed. Scriver CR, Beaudet AL, Sly WS, Valle D (eds). McGraw-Hill, New York 2000.

39. Rall SC Jr, Mahley RW. Type III hyperlipoproteinemia (dysbetalipoproteinemia): the role of apolipoprotein $E$ in normal and abnormal lipoprotein metabolism. In: The Metabolic and Molecular Bases of Inherited Disease. $8^{\text {th }}$ ed. Scriver CR, Beaudet AL, Sly WS, Valle D (eds). McGraw-Hill, New York 2000.

40. Asselbergs FW, Guo Y, van Iperen EP, et al. Large-scale gene-centric meta-analysis across 32 studies identifies multiple lipid loci. Am J Hum Genet 2012; 91: 823-38.

41. Talmud PJ, Shah S, Whittall R, et al. Use of low-density lipoprotein cholesterol gene score to distinguish patients with polygenic and monogenic familial hypercholesterolaemia: a case-control study. Lancet 2013; 381: 1293-301.

42. Ford ES, Li C, Sattar N. Metabolic syndrome and incident diabetes: current state of the evidence. Diabetes Care 2008; 31: 1898-904.

43. Huang PL. A comprehensive definition for metabolic syndrome. Dis Model Mech 2009; 2: 231-7.

44. Soran H, Schofield JD, Adam S, Durrington PN. Diabetic dyslipidaemia. Curr Opin Lipidol 2016; 27: 313-22.

45. Schofield JD, Liu Y, Rao-Balakrishna P, Malik RA, Soran H. Diabetes dyslipidemia. Diabetes Ther 2016; 7: 203-19.

46. Brahm AJ, Hegele RA. Combined hyperlipidemia: familial but not (usually) monogenic. Curr Opin Lipidol 2016; 27: 131-40. 
47. Poobalan A, Aucott L, Smith WC, et al. Effects of weight loss in overweight/obese individuals and long-term lipid outcomes: a systematic review. Obes Rev 2004; 5: 43-50.

48. Van Gaal LF, Mertens IL, Ballaux D. What is the relationship between risk factor reduction and degree of weight loss? Eur Heart J Suppl 2005; 7 (suppl L): L21-6.

49. James J, Thomas P, Cavan D, Kerr D. Preventing childhood obesity by reducing consumption of carbonated drinks: cluster randomised controlled trial. BMJ 2004; 328: 1237.

50. Clarke R, Frost C, Collins R, Appleby P, Peto R. Dietary lipids and blood cholesterol: quantitative meta-analysis of metabolic ward studies. BMJ 1997; 314: 112-7.

51. Haq IU, Yeo WW, Jackson PR, Ramsay LE. The effects of dietary change on serum cholesterol. Proc Nutr Soc 1995; 54: 601-16.

52. Estruch R, Ros E, Salas-Salvado J, et al. Primary prevention of cardiovascular disease with a Mediterranean diet. N Engl J Med 2013; 368: 1279-90.

53. Durrington PN, Bhatnagar D, Mackness MI, et al. An omega-3 polyunsaturated fatty acid concentrate administered for one year decreased triglycerides in simvastatin treated patients with coronary heart disease and persisting hypertriglyceridaemia. Heart 2001; 85: 544-8.

54. Authors/Task Force M, Catapano AL, Graham I, De Backer G, et al. 2016 ESC/EAS Guidelines for the Management of Dyslipidaemias: The Task Force for the Management of Dyslipidaemias of the European Society of Cardiology (ESC) and European Atherosclerosis Society (EAS) Developed with the special contribution of the European Assocciation for Cardiovascular Prevention \& Rehabilitation (EACPR). Atherosclerosis 2016; 253: 281-344.

55. Cholesterol Treatment Trialists C, Mihaylova B, Emberson J, Blackwell L, et al. The effects of lowering LDL cholesterol with statin therapy in people at low risk of vascular disease: meta-analysis of individual data from 27 randomised trials. Lancet 2012; 380: 581-90.

56. Taylor F, Huffman MD, Macedo AF, et al. Statins for the primary prevention of cardiovascular disease. Cochrane Database Syst Rev 2013; 1: CD004816.

57. Stone NJ, Robinson JG, Lichtenstein AH, et al. 2013 ACC/AHA guideline on the treatment of blood cholesterol to reduce atherosclerotic cardiovascular risk in adults: a report of the American College of Cardiology/American Heart Association Task Force on Practice Guidelines. Circulation 2014; 129 (25 Suppl. 2): S1-45.

58. Scottish Intercollegiate Guidelines Network. Risk estimation and the prevention of cardiovascular disease. A clinical guideline 2007. Available at: http://www. sign.ac.uk/assets/sign149.pdf.

59. Neil HA, Mant D, Jones L, Morgan B, Mann J. Lipid screening: is it enough to measure total cholesterol concentration? BMJ 1990; 301: 584-7.

60. Collins GS, Altman DG. Predicting the 10 year risk of cardiovascular disease in the United Kingdom: independent and external validation of an updated version of QRISK2. BMJ 2012; 344: e4181.

61. Hippisley-Cox J, Coupland C, Brindle P. Development and validation of QRISK3 risk prediction algorithms to estimate future risk of cardiovascular disease: prospective cohort study. BMJ 2017; 357: j2099.

62. Goff DC Jr, Lloyd-Jones DM, Bennett G, et al. 2013 ACC/ AHA guideline on the assessment of cardiovascular risk: a report of the American College of Cardiology/ American Heart Association Task Force on Practice Guidelines. Circulation 2014; 129 (25 Suppl. 2): S49-73.
63. Singh N, Kwok S, Seneviratne CJ, France M, Durrington P. The National Cholesterol Education Program III scoring system for CHD risk estimation cannot be used with European recommendations. Br J Cardiol 2004; 11: 282-6.

64. Manuel DG, Kwong K, Tanuseputro P, et al. Effectiveness and efficiency of different guidelines on statin treatment for preventing deaths from coronary heart disease: modelling study. BMJ 2006; 332: 1419.

65. Giugliano RP, Pedersen TR, Park JG, et al. Clinical efficacy and safety of achieving very low LDL-cholesterol concentrations with the PCSK9 inhibitor evolocumab: a prespecified secondary analysis of the FOURIER trial. Lancet 2017; 390: 1962-71.

66. Hovingh GK, Boekholdt SM, Stroes ES. Very low LDL-cholesterol concentrations achieved: which target is next? Lancet 2017; 390: 1930-1.

67. Sabatine MS, Giugliano RP, Keech AC, et al. Evolocumab and clinical outcomes in patients with cardiovascular disease. N Engl J Med 2017; 376: 1713-22.

68. Martin SS, Blaha MJ, Elshazly MB, et al. Comparison of a novel method vs the Friedewald equation for estimating low-density lipoprotein cholesterol levels from the standard lipid profile. JAMA 2013; 310: 2061-8.

69. Boekholdt SM, Arsenault BJ, Mora S, et al. Association of LDL cholesterol, non-HDL cholesterol, and apolipoprotein B levels with risk of cardiovascular events among patients treated with statins: a meta-analysis. JAMA 2012; 307: 1302-9.

70. Brunzell JD, Davidson M, Furberg CD, et al. Lipoprotein management in patients with cardiometabolic risk: consensus conference report from the American Diabetes Association and the American College of Cardiology Foundation. J Am Coll Cardiol 2008; 51: 1512-24.

71. Anderson TJ, Gregoire J, Hegele RA, et al. 2012 update of the Canadian Cardiovascular Society guidelines for the diagnosis and treatment of dyslipidemia for the prevention of cardiovascular disease in the adult. Can J Cardiol 2013; 29: 151-67.

72. Banach M, Jankowski P, Jozwiak J, et al. PoLA/CFPiP/ PCS guidelines for the management of dyslipidaemias for family physicians 2016. Arch Med Sci 2017; 13: 1-45.

73. Piepoli MF, Hoes AW, Agewall S, et al. 2016 European Guidelines on cardiovascular disease prevention in clinical practice: The Sixth Joint Task Force of the European Society of Cardiology and Other Societies on Cardiovascular Disease Prevention in Clinical Practice (constituted by representatives of 10 societies and by invited experts) Developed with the special contribution of the European Association for Cardiovascular Prevention \& Rehabilitation (EACPR). Eur Heart J 2016; 37: 2315-81.

74. Baigent C, Keech A, Kearney PM, et al. Efficacy and safety of cholesterol-lowering treatment: prospective meta-analysis of data from 90,056 participants in 14 randomised trials of statins. Lancet 2005; 366: 1267-78.

75. Soran H, Kwok S, Adam S, Ho JH, Durrington PN. Evidence for more intensive cholesterol lowering. Curr Opin Lipidol 2017; 28: 291-9.

76. Soran H, Dent R, Durrington P. Evidence-based goals in LDL-C reduction. Clin Res Cardiol 2017; 106: 237-48.

77. Boekholdt SM, Hovingh GK, Mora S, et al. Very low levels of atherogenic lipoproteins and the risk for cardiovascular events: a meta-analysis of statin trials. J Am Coll Cardiol 2014; 64: 485-94. 
78. LaRosa JC, Grundy SM, Kastelein JJ, et al. Safety and efficacy of atorvastatin-induced very low-density lipoprotein cholesterol levels in patients with coronary heart disease (a post hoc analysis of the treating to new targets [TNT] study). Am J Cardiol 2007; 100: 747-52.

79. Hsia J, MacFadyen JG, Monyak J, Ridker PM. Cardiovascular event reduction and adverse events among subjects attaining low-density lipoprotein cholesterol $<50$ $\mathrm{mg} / \mathrm{dl}$ with rosuvastatin. The JUPITER trial (Justification for the Use of Statins in Prevention: an Intervention Trial Evaluating Rosuvastatin). J Am Coll Cardiol 2011; 57: 1666-75.

80. Wiviott SD, Cannon CP, Morrow DA, et al. Can low-density lipoprotein be too low? The safety and efficacy of achieving very low low-density lipoprotein with intensive statin therapy: a PROVE IT-TIMI 22 substudy. J Am Coll Cardiol 2005; 46: 1411-6.

81. Cannon CP, Blazing MA, Giugliano RP, et al. Ezetimibe added to statin therapy after acute coronary syndromes. N Engl J Med 2015; 372: 2387-97.

82. Ray KK, Ginsberg HN, Davidson MH, et al. Reductions in atherogenic lipids and major cardiovascular events: a pooled analysis of 10 ODYSSEY trials comparing alirocumab with control. Circulation 2016; 134: 1931-43.

83. Silverman MG, Ference BA, Im K, et al. Association between lowering LDL-C and cardiovascular risk reduction among different therapeutic interventions: a systematic review and meta-analysis. JAMA 2016; 316: 1289-97.

84. Nicholls SJ, Puri R, Anderson T, et al. Effect of evolocum$a b$ on progression of coronary disease in statin-treated patients: the GLAGOV randomized clinical trial. JAMA 2016; 316: 2373-84.

85. Group HTRC, Bowman L, Hopewell JC, Chen F, et al. Effects of anacetrapib in patients with atherosclerotic vascular sisease. N Engl J Med 2017; 377: 1217-27.

86. Ridker PM, Revkin J, Amarenco P, et al. Cardiovascular efficacy and safety of bococizumab in high-risk patients. N Engl J Med 2017; 376: 1527-39.

87. Welty FK. Hypobetalipoproteinemia and abetalipoproteinemia. Curr Opin Lipidol 2014; 25: 161-8.

88. Everett BM, Mora S, Glynn RJ, MacFadyen J, Ridker PM. Safety profile of subjects treated to very low low-density lipoprotein cholesterol levels $(<30 \mathrm{mg} / \mathrm{dl})$ with rosuvastatin $20 \mathrm{mg}$ daily (from JUPITER). Am J Cardiol 2014; 114: 1682-9.

89. Giugliano RP, Mach F, Zavitz K, et al. Cognitive function in a randomized trial of evolocumab. $N$ Engl J Med 2017; 377: 633-43.

90. Robinson JG, Rosenson RS, Farnier M, et al. Safety of very low low-density lipoprotein cholesterol levels with alirocumab: pooled data from randomized trials. J Am Coll Cardiol 2017; 69: 471-82.

91. Benn M, Nordestgaard BG, Frikke-Schmidt R, Tybjaerg-Hansen A. Low LDL cholesterol, PCSK9 and HMGCR genetic variation, and risk of Alzheimer's disease and Parkinson's disease: Mendelian randomisation study. BMJ 2017; 357: j1648.

92. Soran H, Schofield JD, Durrington PN. Cholesterol, not just cardiovascular risk, is important in deciding who should receive statin treatment. Eur Heart J 2015; 36: 2975-83.

93. Soran H, Adam S, Durrington PN. Are recent statin recommendations to employ fixed doses and abandon targets effective for treatment of hypercholesterolaemia? Investigation based on number needed to treat. Eur J Prev Cardiol 2017; 24: 76-83.
94. Ursoniu S, Mikhailidis DP, Serban MC, et al. The effect of statins on cardiovascular outcomes by smoking status: a systematic review and meta-analysis of randomized controlled trials. Pharmacol Res 2017; 122: 105-17.

95. Clarke R, Shipley M, Lewington S, et al. Underestimation of risk associations due to regression dilution in long-term follow-up of prospective studies. Am J Epidemiol 1999; 150: 341-53.

96. Emberson JR, Whincup PH, Morris RW, Walker $M$. Re-assessing the contribution of serum total cholesterol, blood pressure and cigarette smoking to the aetiology of coronary heart disease: impact of regression dilution bias. Eur Heart J 2003; 24: 1719-26.

97. Law MR, Wald NJ, Wu T, Hackshaw A, Bailey A. Systematic underestimation of association between serum cholesterol concentration and ischaemic heart disease in observational studies: data from the BUPA study. BMJ 1994; 308: 363-6.

98. Albert MA, Glynn RJ, Buring J, Ridker PM. Impact of traditional and novel risk factors on the relationship between socioeconomic status and incident cardiovascular events. Circulation 2006; 114: 2619-26.

99. Howard VJ, Kleindorfer DO, Judd SE, et al. Disparities in stroke incidence contributing to disparities in stroke mortality. Ann Neurol 2011; 69: 619-27.

100. Tunstall-Pedoe H. The Dundee coronary risk-disk for management of change in risk factors. BMJ 1991; 303: 744-7.

101. British Cardiac S, British Hypertension S, Diabetes UK, Heart UK, Primary Care Cardiovascular S, Stroke A. JBS 2: Joint British Societies' guidelines on prevention of cardiovascular disease in clinical practice. Heart 2005; 91 Suppl 5: v1-52.

102. Liew SM, Jackson R, Mant D, Glasziou P. Should identical CVD risks in young and old patients be managed identically? Results from two models. BMJ Open 2012; 2: e000728.

103. Wald NJ, Simmonds M, Morris JK. Screening for future cardiovascular disease using age alone compared with multiple risk factors and age. PLoS One 2011; 6: e18742.

104. Gemmell I, Heller RF, Payne K, Edwards R, Roland M, Durrington P. Potential population impact of the UK government strategy for reducing the burden of coronary heart disease in England: comparing primary and secondary prevention strategies. Qual Saf Health Care 2006; 15: 339-43.

105. Siontis GC, Tzoulaki I, Siontis KC, loannidis JP. Comparisons of established risk prediction models for cardiovascular disease: systematic review. BMJ 2012; 344: e3318.

106. Durrington PN. Hyperlipidaemia: diagnosis and management. $3^{\text {rd }}$ ed. Hodder Arnold, London 2007; 399.

107. Soran H, Durrington P. Rosuvastatin: efficacy, safety and clinical effectiveness. Expert Opin Pharmacother 2008; 9: 2145-60

108. Jones P, Kafonek S, Laurora I, Hunninghake D. Comparative dose efficacy study of atorvastatin versus simvastatin, pravastatin, lovastatin, and fluvastatin in patients with hypercholesterolemia (the CURVES study). Am J Cardiol 1998; 81: 582-7.

109. Hobbs FD, Banach M, Mikhailidis DP, Malhotra A, Capewell $\mathrm{S}$. Is statin-modified reduction in lipids the most important preventive therapy for cardiovascular disease? A pro/con debate. BMC Med 2016; 14 : 4.

110. Sahebkar A, Kotani K, Serban C, et al. Statin therapy reduces plasma endothelin-1 concentrations: a meta- 
H. Soran, S. Adam, J.B. Mohammad, J.H. Ho, J.D. Schofield, S. Kwok, T. Siahmansur, Y. Liu, A.A. Syed, S.S. Dhage, C. Stefanutti, R. Donn, R.A. Malik, M. Banach, P.N. Durrington

analysis of 15 randomized controlled trials. Atherosclerosis 2015; 241: 433-42.

111. Banach M, Serban C, Sahebkar A, et al. Impact of statin therapy on coronary plaque composition: a systematic review and meta-analysis of virtual histology intravascular ultrasound studies. BMC Med 2015; 13: 229.

112. The Food and Drug Administration. Limit Use of $80 \mathrm{mg}$ Simvastatin 2011. Available at: https://www.fda.gov/ forconsumers/consumerupdates/ucm257884.htm.

113. Banach M, Rizzo M, Toth PP, et al. Statin intolerance an attempt at a unified definition. Position paper from an International Lipid Expert Panel. Arch Med Sci 2015; 11: 1-23.

114. Rosenson RS, Baker S, Banach M, et al. Optimizing cholesterol treatment in patients with muscle complaints. J Am Coll Cardiol 2017; 70: 1290-301.

115. Armitage J. The safety of statins in clinical practice. Lancet 2007; 370: 1781-90.

116. Pandor A, Ara RM, Tumur I, et al. Ezetimibe monotherapy for cholesterol lowering in 2,722 people: systematic review and meta-analysis of randomized controlled trials. J Intern Med 2009; 265: 568-80.

117. National Institute for Health and Clinical Excellence. Ezetimibe for treating primary heterozygous-familial and non-familial hypercholesterolaemia 2007. Available at: https://www.nice.org.uk/guidance/ta385.

118. Sharp Collaborative G. Study of Heart and Renal Protection (SHARP): randomized trial to assess the effects of lowering low-density lipoprotein cholesterol among 9,438 patients with chronic kidney disease. Am Heart J 2010; 160: 785-94 e10.

119. Serban MC, Banach M, Mikhailidis DP. Clinical implications of the IMPROVE-IT trial in the light of current and future lipid-lowering treatment options. Expert Opin Pharmacother 2016; 17: 369-80.

120. The Lipid Research Clinics Coronary Primary Prevention Trial results. I. Reduction in incidence of coronary heart disease. JAMA 1984; 251: 351-64.

121. Cicero AFG, Colletti A, Bajraktari G, et al. Lipid lowering nutraceuticals in clinical practice: position paper from an International Lipid Expert Panel. Arch Med Sci 2017; 13: 965-1005.

122. Loomba RS, Arora R. Prevention of cardiovascular disease utilizing fibrates: a pooled meta-analysis. Am J Ther 2010; 17: e182-8.

123. Lee M, Saver JL, Towfighi A, Chow J, Ovbiagele B. Efficacy of fibrates for cardiovascular risk reduction in persons with atherogenic dyslipidemia: a meta-analysis. Atherosclerosis 2011; 217: 492-8.

124. Lavigne PM, Karas RH. The current state of niacin in cardiovascular disease prevention: a systematic review and meta-regression. J Am Coll Cardiol 2013; 61: 440-6.

125. Group HTC, Landray MJ, Haynes R, et al. Effects of extended-release niacin with laropiprant in high-risk patients. N Engl J Med 2014; 371: 203-12.

126. Rizos EC, Ntzani EE, Bika E, Kostapanos MS, Elisaf MS. Association between omega-3 fatty acid supplementation and risk of major cardiovascular disease events: a systematic review and meta-analysis. JAMA 2012; 308: 1024-33.

127. Jaworski K, Jankowski P, Kosior DA. PCSK9 inhibitors from discovery of a single mutation to a groundbreaking therapy of lipid disorders in one decade. Arch Med Sci 2017; 13: 914-29.

128. National Institute of Clinical Health and Excellence (NICE). Evolocumab for treating primary hypercholes terolaemia and mixed dyslipidaemia. Technical Appraisal Guidance [TA394]. London: NICE; 2016. Available from: https://www.nice.org.uk/guidance/ta394.

129. National Institute of Clinical Health and Excellence (NICE). Alirocumab for treating primary hypercholesterolaemia and mixed dyslipidaemia London: NICE; 2016. Available from: https://www.nice.org.uk/guidance/ta393.

130. Buchwald H, Varco RL, Matts JP, et al. Effect of partial ileal bypass surgery on mortality and morbidity from coronary heart disease in patients with hypercholesterolemia. Report of the Program on the Surgical Control of the Hyperlipidemias (POSCH). N Engl J Med 1990; 323: 946-55.

131. Palacio CH, Harring TR, Nguyen NT, Goss JA, O'Mahony CA. Homozygous familial hypercholesterolemia: case series and review of the literature. Case Rep Transplant 2011; 2011: 154908.

132. Carswell KA, Belgaumkar AP, Amiel SA, Patel AG. A systematic review and meta-analysis of the effect of gastric bypass surgery on plasma lipid levels. Obes Surg 2016; 26: 843-55.

133. Yadav R, Hama S, Liu Y, et al. Effect of Roux-en-Y bariatric surgery on lipoproteins, insulin resistance, and systemic and vascular inflammation in obesity and diabetes. Front Immunol 2017; 8: 1512. doi: 10.3389/ fimmu.2017.01512.

134. Kennedy-Dalby A, Adam S, Ammori BJ, Syed AA. Weight loss and metabolic outcomes of bariatric surgery in men versus women - a matched comparative observational cohort study. Eur J Intern Med 2014; 25: 922-5.

135. Aghamohammadzadeh R, Greenstein AS, Yadav R, et al. Effects of bariatric surgery on human small artery function: evidence for reduction in perivascular adipocyte inflammation, and the restoration of normal anticontractile activity despite persistent obesity. J Am Coll Cardiol 2013; 62: 128-35.

136. Yadav R, France M, Aghamohammadzadeh R, et al. Impairment of high-density lipoprotein resistance to lipid peroxidation and adipose tissue inflammation in obesity complicated by obstructive sleep apnea. J Clin Endocrinol Metab 2014; 99: 3390-8.

137. Millichamp KA, Cooper V, Syed AA. Immediate changes in continuous positive airway pressure after bariatric surgery in obese people with obstructive sleep apnoea. Eur J Intern Med 2014; 25: e33-4.

138. Buchwald H, Avidor $\mathrm{Y}$, Braunwald $\mathrm{E}$, et al. Bariatric surgery: a systematic review and meta-analysis. JAMA 2004; 292: 1724-37.

139. Thompson GR, Catapano A, Saheb S, et al. Severe hypercholesterolaemia: therapeutic goals and eligibility criteria for LDL apheresis in Europe. Curr Opin Lipidol 2010; 21: 492-8.

140. Marais AD, Blom DJ. Recent advances in the treatment of homozygous familial hypercholesterolaemia. Curr Opin Lipidol 2013; 24: 288-94.

141. Moriarty PM, Parhofer KG, Babirak SP, et al. Alirocum$\mathrm{ab}$ in patients with heterozygous familial hypercholesterolaemia undergoing lipoprotein apheresis: the ODYSSEY ESCAPE trial. Eur Heart J 2016; 37: 3588-95.

142. Watts GF, Stefanutti C. ODYSSEY ESCAPE: is PCSK9 inhibition the Trojan Horse for the use of lipoprotein apheresis in familial hypercholesterolaemia? Eur Heart J 2016; 37: 3596-9.

143. Stefanutti C, Julius U, Watts GF, et al. Toward an international consensus-integrating lipoprotein apheresis 
and new lipid-lowering drugs. J Clin Lipidol 2017; 11: 858-71e3.

144. France M, Rees A, Datta D, et al. HEART UK statement on the management of homozygous familial hypercholesterolaemia in the United Kingdom. Atherosclerosis 2016; 255: 128-39.

145. Blom DJ, Averna MR, Meagher EA, et al. Long-term efficacy and safety of the microsomal triglyceride transfer protein inhibitor lomitapide in patients with homozygous familial hypercholesterolemia. Circulation 2017; 136: 332-5.

146. McGowan MP, Tardif JC, Ceska R, et al. Randomized, placebo-controlled trial of mipomersen in patients with severe hypercholesterolemia receiving maximally tolerated lipid-lowering therapy. PLoS One 2012; 7: e49006.

147. Di Bartolo BA, Schwarz N, Andrews J, Nicholls SJ. Infusional high-density lipoproteins therapies as a novel strategy for treating atherosclerosis. Arch Med Sci 2017; 13: 210-4

148. Hovingh GK, Smits LP, Stefanutti C, et al. The effect of an apolipoprotein A-I-containing high-density lipoprotein-mimetic particle (CER-001) on carotid artery wall thickness in patients with homozygous familial hypercholesterolemia: The Modifying Orphan Disease Evaluation (MODE) study. Am Heart J 2015; 169: 736-42e1.

149. Kataoka Y, Andrews J, Duong $M$, et al. Regression of coronary atherosclerosis with infusions of the high-density lipoprotein mimetic CER-001 in patients with more extensive plaque burden. Cardiovasc Diagn Ther 2017; 7: 252-63.

150. Van Craeyveld E, Jacobs F, Gordts SC, De Geest B. Gene therapy for familial hypercholesterolemia. Curr Pharm Des 2011; 17: 2575-91.

151. Nikolic D, Rizzo M, Mikhailidis DP, Wong NC, Banach M. An evaluation of RVX-208 for the treatment of atherosclerosis. Expert Opin Investig Drugs 2015; 24: 1389-98.

152. Di Bartolo BA, Scherer DJ, Nicholls SJ. Inducing apolipoprotein A-I synthesis to reduce cardiovascular risk: from ASSERT to SUSTAIN and beyond. Arch Med Sci 2016; 12: 1302-7.

153. Ray KK, Landmesser U, Leiter LA, et al. Inclisiran in patients at high cardiovascular risk with elevated LDL cholesterol. N Engl J Med 2017; 376: 1430-40.

154. Penson P, McGowan M, Banach M. Evaluating bempedoic acid for the treatment of hyperlipidaemia. Expert Opin Investig Drugs 2017; 26: 251-9. 